\title{
Exploring the Dynamics of Global Liquidity
}

Sally Chen, Philip Liu, Andrea Maechler, Chris Marsh, Sergejs Saksonovs, and Hyun Song Shin 


\title{
IMF Working Paper
}

Strategy, Policy, and Review Department

\section{Exploring the Dynamics of Global Liquidity}

\section{By Sally Chen, Philip Liu, Andrea Maechler, Chris Marsh, Sergejs Saksonovs, and Hyun Song Shin*}

Authorized for distribution by Martin Mühleisen

October 2012

\section{This Working Paper should not be reported as representing the views of the IMF.} The views expressed in this Working Paper are those of the author(s) and do not necessarily represent those of the IMF or IMF policy. Working Papers describe research in progress by the author(s) and are published to elicit comments and to further debate.

\begin{abstract}
This paper explores the concept of global liquidity, its measurement and macro-financial importance. We construct two sets of indicators for global liquidity: a quantity series distinguishing between core and noncore liabilities of financial intermediatires and a corresponding price series. Using price and quantity indicators simultaneously, it is possible to distinguish between shocks to the supply and demand for global liquidity, and isolate their impact on the economy. Our results confirm that global liquidity conditions matter for economic and financial stability, and points to indicators whose regular monitoring could be valuable to policymakers.
\end{abstract}

JEL Classification Numbers: G01, G15, G18, G32, C23

Keywords: Liquidity, core and noncore financial liabilities, shadow banking, growth Authors E-Mail Addresses: SChen@,imf.org; philipliu.mail@,gmail.com; AMaechler@imf.org;

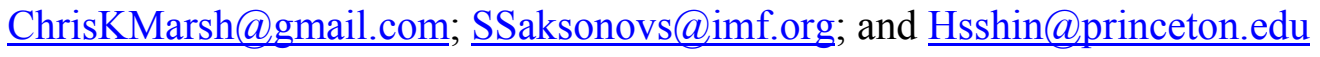

\footnotetext{
*The authors are grateful to Isabelle Mateos y Lago and Martin Mühleisen for their intellectual guidance and to Irena Asmundson, Heedon Kang, Minsuk Kim, Mark Stone, and Tao Sun for contributions to an earlier version. The paper benefited greatly from extensive disucssion with Tam Bayoumi and Laura Kodres, and from comments from Olivier Blanchard, Ricardo Davico, Gianni De Nicolo, Jeanne Gobat, Artak Harutyunyan, Manik Shrestha, Karim Youssef, participants in an IMF seminar, as well as comments from the U.S. Treasury, the Federal Reserve Board and the European Central Bank. Excellent research assistance was provided by Tola Oni.
} 
I. Introduction 4

II. Literature Review .6

III. A New Approach to Measuring Global Liquidity ......................................................

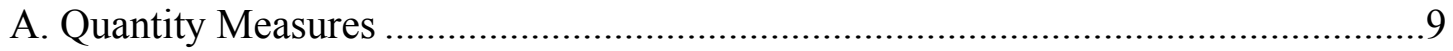

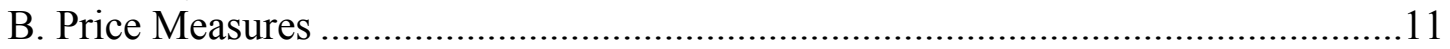

IV. Identifying Drivers of Global Liquidity .................................................................13

A. Aggregate Trends of Core and Noncore Global Liquidity .................................14

B. Country-specific Trends of Core and Noncore Liabilities ....................................15

C. Trends in External Liabilities of Countries to BIS Reporting Banks.......................16

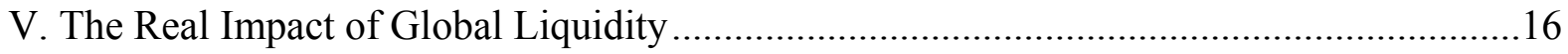

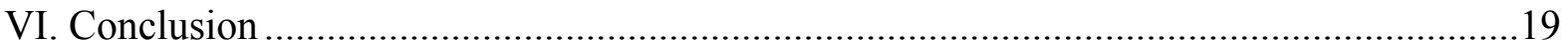

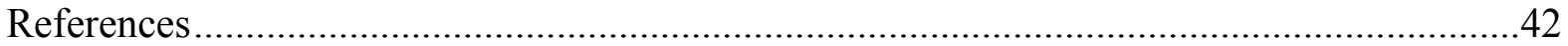

Tables

1. Unit Root Tests of Liquidity Price and Quantity Indicators .........................................36

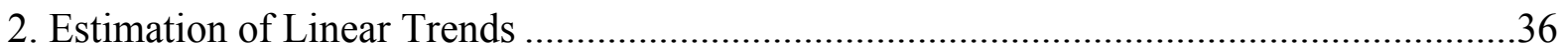

3. Impact of Funding Shocks on Growth: Benchmark Model ............................................37

4. Impact of Funding Shocks on Growth: Separate Time Periods.......................................38

5. Impact of Funding Shocks on Growth: G4-Specific Impacts, Q1 1999-Q1 2011 .............39

Figures

1. Total G4 Liquidity in Trillion Dollars and As a Ratio to GDP .....................................26

2. National Measures of the Quantity of Liquidity, Ratio to National Nominal GDP ...........26

3. National Measures of the Quantity of Liquidity, Trillion US dollars ................................27

4. Total External Liabilities to BIS Reporting Banks ....................................................27

5. Nominal GDP Growth Rates ............................................................................28

6. Supply and Demand Shocks, Quantity and Price of Core Global Liquidity .....................28

7. Supply and Demand Shocks, Quantity and Price of Noncore Global Liquidity ................28

8. Supply and Demand Shocks to Liquidity: United States and Euro Area ..........................29

9. Country-Specific Supply and Demand Shocks: United Kingdom and Japan.....................30

10. Supply and Demand Shocks: External Liabilities of G4 Economies ..............................31

11. Supply and Demand Shocks: External Liabilities of other countries to BIS Reporting

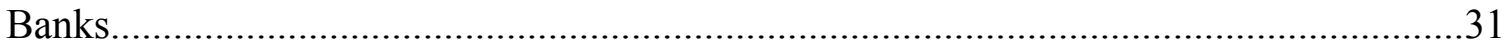

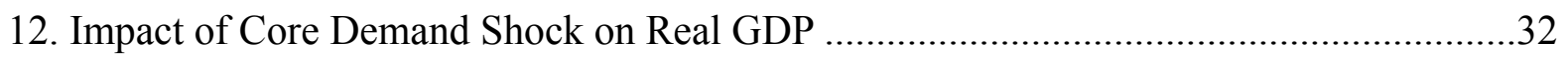

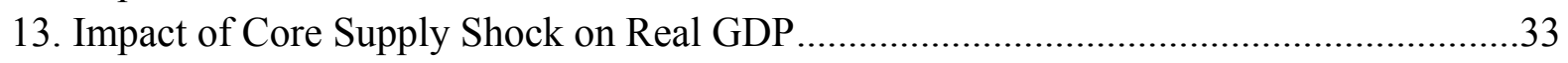

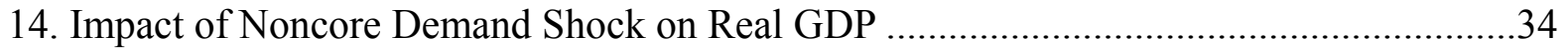

15. Impact of Noncore Supply Shock on Real GDP......................................................35 
Boxes

1. Estimation of the Noncore Liquidity Price Index ......................................................21

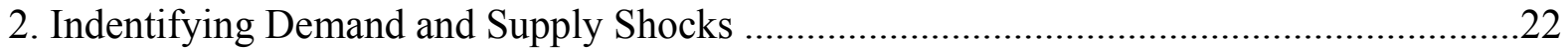

3. A Panel Regression Approach to Assessing the Real Impact of Global Liquidity.............23

4. A VAR Approach to Assessing the Real Impact of Global Liquidity ...............................24

Appendix: Measuring G4 Core and Noncore Liabilities ..............................................40 


\section{INTRODUCTION}

Recent financial crises in the U.S. and Europe have brought the impact of liquidity on economic and financial stability into sharp relief. Much of this impact has long been documented. Domestically, liquidity has been seen as having important implications for the real economy and the financial system (for example Friedman and Schwarz, 1963). It can drive up asset prices and encourage risk-taking, with negative consequences for financial stability (Borio and Zhu, 2008). Globally, the allocation liquidity affects macroeconomic and financial developments in ways that are not directly under the control of national policymaker (a theme of recent GFSR and spillover reports, see IMF, 2011a; IMF, 2011b; IMF, 2011c; IMF, 2011d; also Matsumoto, 2011; and Darius and Radde, 2010).

At the most basic level, liquidity can be described as the amount of funding readily available to finance domestic and cross-border asset purchases. Liquidity reflects both the ability and willingness of parties to engage in financial transactions, including intermediation, as well as the capacity of financial markets to absorb temporary fluctuations in demand and supply without undue dislocations in prices. In part because of the many purposes liquidity serves, there is no straightforward way to assess developments in global liquidity conditions. ${ }^{1}$

One challenge in measuring liquidity is that it is largely endogenous and highly cyclical, contributing to the build-up of risks to financial stability and be affected by them in return. While central bank injection of base money plays an important role in liquidity creation, flows in global liquidity are also driven by growth differentials, financial innovation, and market participants' risk appetite (CGFS, 2011). For example, the recent explosion of collateralized market-based borrowing, where funding expands or contracts depending on the market value of the underlying collateral, has introduced a significant source of endogeneity (IMF, 2011e, 2011f, 2011g). Similarly, if for some reason, private agents become unwilling to transact, much of the liquidity can disappear and the same amount of liquidity as measured by quantity aggregates may go from being abundant to scarce, with attendant price increases, while exacerbating the potentially volatile nature of liquidity.

The case for monitoring global liquidity conditions is not straightforward. While there is conflicting evidence whether national monetary aggregates contain useful information about the business cycles, and possible asset price misalignments ${ }^{2}$, the value of aggregating national monetary aggregates is particularly questionable given their differences. Domestic quantity measures of money aggregates have fallen out of fashion in some countries, such as the United States, because of the lack of empirically-stable relations between money

\footnotetext{
${ }^{1}$ This work is an expansion of preliminary work produced in the context of a G-20 work request to help deepen the understanding of the role of global liquidity in the international monetary system.

${ }^{2}$ See, for example, Gerdesmeier, D., Reimers, H.-E. and Roffia, B., 2010; Alessi, L. and Detken, C. 2011 and Box 2 in the ECB Annual Report (2011).
} 
aggregates and macroeconomic variables. At the same time, the global financial crisis has made clear that traditional monetary aggregates on a national level may not capture the full range of liquidity-creating instruments nor the full impact of the activities of large cross border financial intermediaries, which play an increasingly important role in globally integrated capital markets. In particular, the source of funding - whether via deposit funding or wholesale funding - matters. The crisis has also highlighted that financial structure does matter-especially in times of stress, in sharp contrast to the frictionless financial market hypothesis underlying modern monetary theory (Tirole, 2011).

Approaches to liquidity measurement generally fall along two lines: the asset side or the liability side. From the asset side, efforts involve measuring the amount of global credit extended to the private sector, providing valuable insights about the liquidity cycle through the private sector balance sheet expansion. ${ }^{3}$ The liability side approach, adopted in this paper, focuses on the funding available to expand financial institutions' balance sheets and the risks associated with sudden funding reversals, as manifested during the global financial crisis. Put differently, "liquidity" as measured here, is the degree to which institutions can borrow-as measured by the liability side of the balance sheets - and to expand and contract balance sheets through increases in leverage or consolidation based on collateral valuations. A key advantage of the current funding-based approach is that it aims at capturing not only bankbased financial intermediation but also the broader range of wholesale intermediation, something which has proven difficult to do on the credit side.

The use of price and quantity measures together can help better understand developments in liquidity conditions. Quantity indicators, which reflect the size of the risk exposure, tend to be slow-moving, making them ill-suited as forward-looking indicators of crises. ${ }^{4}$ Similarly, price indicators are coincident indicators, spiking only when the crisis is already underway, making them equally poor early warning indicators. ${ }^{5}$ Combining the behavior of prices and quantities provides a richer framework of analysis. It sheds light on the paradox of risk management, where risk (as reflected by the size of exposures) is often at its highest when its perception (as reflected by the price of funding) is at its lowest. Additionally, analyzing price and quantity measures together helps disentangling the pull- and push-factors driving the behavior of liquidity. Persistent increases in liquidity supply - for example, driven by financial innovations - would result in growing liquidity (quantity) and falling interest rates (prices). By contrast, higher demand for liquidity — driven by rising risk appetite and

\footnotetext{
${ }^{3}$ Recent work using this approach include, for example, Borio, McCauley, and McGuire, 2011; Borio and Disyatat, 2011; CGFS, 2012; Domanski, Fender, and McGuire, 2011; and Jorda, Schularick and Taylor, 2011.

${ }^{4}$ The slow-moving nature of quantity-based indicators is true even after removing linear trends and when considered on a gross basis (i.e., not as a ratio of liquidity to GDP).

${ }^{5}$ This finding is robust across a variety of global liquidity price indicators (e.g., VIX considered by CGFS, various spreads and asset price based indicators considered in IMF 2011a, 2011b, 2011c).
} 
expectations of higher returns - would result in increases in both price and quantity measures.

Important caveats are in order. First and foremost, there is no theoretical framework to determine an optimal level of global liquidity, nor do we know how global liquidity should behave to promote sound, sustainable global growth with financial stability. Second, financial markets are undergoing rapid transformation, the underlying reality that these indicators try to capture is therefore constantly evolving, at a rapid pace. Finally, serious data shortcomings remain - for example, only a few countries compute flow of funds data while cross-country reporting consistency is still lacking. Thus, any policy conclusions from our measurement exercises should depend on a thorough analysis of the underlying developments. More research is needed to improve the measurement of liquidity and develop a theoretical basis for understanding its economic and financial implications.

The paper is structured as follows: in section II, we review the literature on liquidity, summarizing findings that connect narrow money with broad money, and assess the impact of liquidity on output, price level and commodity prices. We also discuss findings on the developments in collateral-based funding markets where the shadow banking system has played an increasingly important role. In section III, we propose a new approach to measuring liquidity, offering complementary quantity and price measures that provide a more complete assessment of liquidity developments. Using these price and quantity indicators for core and noncore liquidity, in section IV, we identify supply and demand drivers of liquidity changes. In section $\mathrm{V}$, we assess the drivers of liquidity on growth and find that the nature of shocks - supply or demand - and the types of liquidity affected - core or noncore - matter greatly in the effect on growth. Lastly, we conclude in section VI.

\section{LiteratURE REVIEW}

Traditionally, the literature has used monetary aggregates as proxies for the quantity of liquidity, focusing on the money multiplier connecting narrow money (cash and other claims on the central bank) with broad money (the deposit liabilities of the banking sector). One strand of literature explores the impact of monetary aggregates from major countries on real economic variables. Sousa and Zaghini (2004) find that changes in global (excluding euro) liquidity explain an important share of the euro area price and output fluctuations. Ruffer and Stracca (2006) find that a positive shock to global excess liquidity (defined as the ratio between broad money to nominal GDP) leads to a significant rise in domestic real output and

price level for the euro area and Japan. Additionally, global liquidity has a significant impact on asset and commodity prices (Darius and Radde, 2010, for global house prices; Thomas, Muhleisen and Pant, 2010, for world oil prices; and Psalida and Tao, 2011, for the impact of G4 liquidity expansion on asset prices in the rest of the world).

As financial systems move away from traditional deposit-based funding to capital and, more recently, collateral-based markets, standard monetary aggregates have become less suited to 
capture movements in the globally available funding. In recent years, much work has focused on capturing the role of the shadow banking system. Adrian, Ashcraft, Boesky and Poszar (2010) find that the volume of credit intermediated by the shadow banking system has far exceeded that of the traditional banking system since the mid-1990s. Adrian and Shin (2010) find that the balance sheet expansion of investment banks is a good proxy for overall funding conditions in market-based financial systems. ${ }^{6}$

Another strand of literature has focused on exploring cross-border liquidity linkages. Shin and Shin (2011) find that an increase in noncore liabilities (defined as the sum of foreign exchange bank liabilities and wholesale bank funding) is found to be a good predictor of an appreciation in the Won and rising credit spreads in Korea. McGuire and von Goetz (2009) find that European banks' reliance on interbank borrowing and dollar funding exposed them to funding risk and balance sheet pressure during the financial crisis. Bruno and Shin (2011) focus on the fluctuating leverage of cross-border banks as the channel through which financial conditions are transmitted globally.

The financial crisis highlighted the role of collateralized borrowing in amplifying risk propagation mechanisms (Bernanke and Gertler, 1989, Kiyotaki and Moore, 1997, and Bernanke, Gertler and Gilchrist, 1999). Leverage, with its self-reinforcing feedback loops on asset valuation and macroeconomic stability, is gaining increasing attention. Brunnermeier (2009) and Adrian and Shin (2010) find that the creation (and destruction) of credit to the private sector is increasingly tied to institutions' ability to leverage their balance sheets. The study of 14 developed countries over 140 years by Jorda et al (2011) finds credit growth as the single best predictor of financial instability. Furthermore, pro-cyclical margin requirements can create liquidity spirals, whereby a small loss in equity price that prompts a margin call could result in a fire sale of assets, further exacerbating the initial equity loss and needed deleveraging (Geanakoplos, 2009, Brunnermeier and Sannikov, 2010). Following the financial crisis, Singh (2011) finds that the use and reuse of collateral help "lubricate" the financial system; a significant decline in such collateral — a result of more stringent regulations and crimped risk appetites_-will likely reduce market liquidity.

\section{A New Approach to Measuring Global LiQuidity}

The global financial crisis has highlighted structural shifts in the financial system and the importance of moving beyond standard monetary aggregates. The analysis of such aggregates had focused on the transactions role of money and the multiplier that connects narrow money (cash and other claims on the central bank) with broad money (the deposit liabilities of the banking sector). An alternative economic rationale for monetary aggregates is that they are

\footnotetext{
${ }^{6}$ See also Adrian and others (2011) for a discussion on the repo and securities lending market and Poszar (2011) for the role of institutional cash pools as a demand driver for shadow banking activities.
} 
liabilities of depository corporations and so convey information on the extent of risk-taking in the financial system and overall financial conditions (Shin and Shin, 2010).

The rationale for funding markets as a signal of financial conditions derives from their status as the balance sheet counterpart to intermediated lending. Adrian and Shin (2010) highlight the role of measured risks, and in particular the bank's Value-at-Risk (a measure of potential losses for the bank) as a key determinant of the expansion or contraction of the intermediary sector. A good rule of thumb is that banks adjust lending in order to keep their probability of failure constant in the face of changing financial conditions. In periods of market stress, banks contract lending and shed risky exposures, while in tranquil conditions, banks expand lending.

One source of funding available to the banks is the retail deposits of the household sector. Core liabilities could thus be defined as the funding that banks draw on during normal times. What constitutes core funding will depend on the context and the economy in question, but retail deposits of the household sector would be a good instance of core liabilities. Put it differently, as our analysis focuses on the liability side of the balance sheet, households are the suppliers of core liquidity; their decision to supply funding to banks depend in large part on the opportunity costs of deposits as well as their risk appetite for potentially higher yielding, but less stable alternatives. Meanwhile, commercial banks and depository institutions are the consumers of core liquidity. Their reliance on deposit funding reflect, in part, the availability of alternative funding sources and the opportunity costs of accessing these funding elsewhere.

When credit is growing rapidly in a booming economy and funding demand exceeds those supplied by retail deposits, financial institutions may turn to other sources of funding to support the growth of their asset portfolio. In recent years, capital markets, including wholesale as well as collateral-based financing have become a greater source of funding. For these sources of funding, known as "noncore" liabilities in our analysis, financial institutions can be both suppliers and consumers of "noncore" liabilities. For these financial institutions, their financial innovations create new instruments that increase the pool of potential collateral for funding; meanwhile, their needs to finance collateral-based transactions increase demand for noncore funding. In this way, pro-cyclical components of bank liability aggregates will reflect incremental bank lending during episodes of rapid credit growth that may reverse when the cycle turns and financial conditions deteriorate. More generally, bank liability aggregates may be expected to convey information on the degree of risk-taking in the economy giving insights on the vulnerability of the financial system to a reversal.

Our analysis explores the information value of "core" and "noncore" liabilities (quantity measures), as well as related price measures (based on funding costs). As advanced economy financial systems have moved beyond traditional deposit-taking banks toward increased dependence on capital markets, in order to capture liquidity conditions more accurately, traditional monetary aggregates will need to be supplemented with other items from bank and 
nonbank financial institutions' balance sheets. This suggests a taxonomy that distinguishes "core" liabilities such as retail bank deposits that are relatively stable components of intermediary liabilities from "noncore" liabilities that co-vary more with the financial cycle (Chart 1).

\section{A. Quantity Measures}

This paper defines the quantity of global liquidity as the sum of financial sector liabilities of the euro area, Japan, the United Kingdom, and the United States, henceforth referred to as the "G4" economies.

Global liquidity is computed by aggregating the individual liquidity series across the G4 economies. To control for inflation and economic growth, the G4 aggregates are expressed in U.S. dollars and normalized by the (U.S. dollar denominated) nominal GDP of the four countries. ${ }^{8}$ The quantity measures of global liquidity are shown in Figure 1, both in trillions of U.S. dollars and as a ratio to GDP, while country-specific measures are presented in Figure 2 (as a ratio to nominal GDP) and Figure 3 (in trillions of US dollars). ${ }^{9}$ Financial liabilities are taken from the aggregate financial sector balance sheets captured in the flow of funds accounts of the respective economies. These balance sheets capture liquidity provided not only by banks but also by nonbank intermediaries who raise funding in the capital market on a collateralized basis. We also include money market funds as they have been known to play an important role in providing funding to financial intermediaries. ${ }^{10}$ For completeness, we have also included the liabilities of insurance companies and pension funds (Chart 1). In particular, we explore the distinction between core (deposit-based) liquidity (funding) and noncore liquidity, sometimes referred to as "shadow banking" funding (see Appendix for more details). ${ }^{11}$

\footnotetext{
${ }^{7}$ Given their size and central role in intermediating funds globally, liquidity in the G4 economies is a good proxy for global conditions. For example, the G4 have accounted for between 82 and 92 percent of total BIS external claims since 1995.

${ }^{8}$ In practice, a linear deterministic trend is removed from the quantity indicators, in line with the quantity theory of money, which assumes a linear relationship between nominal GDP and the stock of financial sector liabilities. The US dollars denomination is driven by the observation that much of financial sector liabilities are denominated in US dollars.

${ }^{9}$ In the case of Japan, liabilities (in trillions of dollars) are less volatile than when measured as a ratio to nominal GDP, because the Japanese nominal GDP declined several times over the sample period (Figure 5).

${ }^{10}$ Prime money market funds in the United States have held roughly 70 to 80 percent of their assets in the liabilities of the banking sector in recent years (see the IMF Global Financial Stability Report, September 2011, Chapter 1).

${ }^{11}$ We rely on flow of funds data from the central banks and classify funding based on the instruments involved. This is distinct from the measure presented by Poszar and others (2010), which is based on institutions. Despite these differences, our measures remain broadly consistent. Detailed dataset underlying the results of this paper are available from the authors upon request.
} 
- Core liquidity is defined as total resident deposits in commercial banks and other depositary corporations. Broadly, this series is similar to what is captured by the traditional broad money aggregates, particularly M3. ${ }^{12}$ In line with the traditional monetary aggregates, this series does not include inter-bank deposits (e.g., deposits of other financial institutions with commercial banks and other depositary corporations) as these deposits do not typically represent a source of "liquidity" for the nonfinancial private sector-i.e., they do not create leverage.

- $\quad$ Noncore liquidity is defined as the total nonresident deposits in commercial banks (hence cross-border deposits would be considered noncore) and other deposit corporations as well as loans and securities (other than shares) of commercial banks, nonbanks and other financial intermediaries. In contrast to core liquidity, this series includes liabilities across financial institutions. As financial institutions can be on both sides of the balance sheet and collaterals lent or borrowed can contribute to the degree of leverage, capturing liabilities across financial institutions helps to better assess the gross amount of leverage — and correspondingly, funding — available.

Overall, the differences in the behavior between core and noncore global liquidity suggest the need to monitor each component separately. Global liquidity has more than doubled since 1999 in nominal terms. Two thirds of the rise is attributable to noncore liquidity, particularly since 2004. During the upswing, prior to the global financial crisis, noncore liquidity in the G4 was the key driver, with core funding (relative to GDP) remaining flat, as financial institutions relied increasingly on endogenous "money" creation to fund their expansion. ${ }^{13}$ Once the crisis struck, noncore funding contracted, and core funding partially filled the gap - reflecting the exceptional policy support during the crisis - provided by central bank liquidity injections. Overall, these trends confirm the procyclicality of some global liquidity components and suggest that monitoring developments in the noncore "shadow banking" aggregates may provide useful insights on the developments in the financial sector and their implications for real economy.

As an additional robustness check, we also consider countries' external liabilities to BIS reporting banks as a proxy for global liquidity (Figure 4), detrended as the quantity measures above. In particular, we focus on both G4 economies and a broader set of advanced and emerging economies (see Section V). We find that while the external liabilities of our nonG4 sample of economies account for only about one quarter of the G4 external liabilities in size, they tend to be larger when measured as a ratio of GDP, highlighting their crucial role

\footnotetext{
${ }^{12}$ This does not, however, imply that the two measures are equivalent.

${ }^{13}$ For example, noncore global liquidity experienced deviations from trend of around 15 percent of G4 GDP, while these deviations were around 6 percent in the case of core liquidity.
} 
in complementing limited domestic funding needs. After the onset of the global financial crisis in 2008, the external liabilities of the non-G4 economies recovered both in levels and as a ratio to GDP (reflecting partly the sharp decline of nominal GDP), whereas the G4 external liabilities have continued to fall, both in absolute terms and as a ratio to GDP.

\section{B. Price Measures}

Having identified core and noncore liquidity in Section A, it is necessary to develop their corresponding price measures:

- The price of core liquidity is defined as the spread between domestic deposit rate for deposits with a maturity of up to one year and the 6-month interbank offered rate (Figures 8 and 9). Spreads, which are used to control for the monetary policy cycle, are standardized to account for cross-border differences in the statistical deposit coverage. A widening in the spread signals an increase in the relative marginal cost of deposit funding. At the global level, the price for global core liabilities is defined as the weighted average of individual countries' standardized spreads, with the weights corresponding to a country' core liabilities as a ratio of global core liabilities (Figure 6).

- A Noncore Liquidity Price Index (NLPI) captures the marginal cost of noncore funding. Conceptually, the price of noncore funding is relatively more difficult to identify, since it covers a variety of instruments (e.g., bank-issued commercial paper, repo deals, etc.), which may each be governed by different institutional arrangements. Thus, we include variables such as interest rate spreads, asset prices, credit volume as well as lending condition surveys to better capture the costs of noncore funding. The index is constructed using a dynamic factor model, which assumes that each chosen indicator can be decomposed into a common component and an idiosyncratic component (Box 1).${ }^{14}$ We define a price for noncore liquidity, both at the global and country-specific level. The country-specific and global NLPIs are plotted in Figures 6-9.

Our price measures are assumed to measure the price of the entire stock of liabilities, which may have been accumulated over time, under different financial conditions (e.g., bonds that were issued with different coupon rates). The rationale for this is that, if all or part of these liabilities would need to be refinanced at a given moment in time, it is the financial conditions of that particular period that would determine the price for the funding necessary to refinance.

\footnotetext{
${ }^{14}$ See Matheson (2011) for the full list of indicators included. The index, which includes quantitative measures to capture the general business climate (e.g., via loan officer surveys), is in standard deviations from the average, with the financial crisis of 2008 at four standard deviations.
} 
The global NLPI captures the unprecedented tightening of financial conditions during the global financial crisis (Figures 8 and 9). In 2008, for example, the global NLPI jumped by more than four standard deviations. The country-specific NLPI also peaked in 2008, with some important cross-country differences, particularly in Japan, where the price and quantity of noncore liquidity saw smaller fluctuations than in the other three G4 economies.

\section{Liquidity Supply and Demand}

Understanding the nature of liquidity shocks is crucial for drawing policy conclusions. It is useful to have in mind a model of the structure of the relationships between various parts of the financial sector and nonfinancial sector and thus, to identify who supplies and demands which kinds of funding.

For core liquidity, we assume that the nonfinancial sector is on the supply side, while retail banks and money market funds are on the demand side (see Chart 1). Thus, for example, a positive supply shock to core liquidity can stem from household investors shifting to less risky assets, such as bank deposits, in response to deteriorating fundamentals, (e.g., "flightto-safety" behavior, lack of profitable investment opportunities, etc.). On the other hand, positive demand shocks to core funding can occur when banks are forced to raise more stable (and expensive) funding, possibly arising from regulatory changes or the drying up of alternative funding sources during financial market stress.

For noncore liquidity, financial institutions can be on both the supply and demand side of the transaction, as financial intermediaries may borrow in order to lend further. In addition, as collateral may be used multiple times - through the process of rehypothecation-our noncore liquidity quantity aggregate may involve a certain amount of double counting. Still, such double counting may be necessary to better capture changes in leverage within the financial system. A positive supply shock to noncore liquidity may stem from "inside" money creation, as global banks raise funding in wholesale market to leverage and expand their balance sheets against a backdrop of low prices for liquidity. An easing in the financial conditions can be associated with higher risk appetite (e.g., the Great Moderation) and procyclical increases in leverage. A positive demand shock to noncore liquidity, on the other hand, can occur when financial institutions face high rollover funding needs in an environment of deteriorating economic fundamentals (falling GDP) and are willing to bid up the price of noncore funding.

Periods of persistent increasing liquidity supply — for example, driven by inside money creation, with growing liquidity (quantities) and falling interest rates (prices) - are often associated with increased risk taking and leverage in the financial sector, and hence may require macro-financial measures to counteract or discourage risk taking. On the other hand, periods of growing demand for liquidity may reflect expectations of higher return on investment, raising the demand for funds. This scenario may not require a strong regulatory response (though, admittedly, this change still requires attention if expectations of future 
productivity gains from innovation lead to overinvestment-e.g., the dotcom bubble). It is important to emphasize the behavior of prices in these scenarios. Periods of positive supply act to lower the price of funding, which increases vulnerability to a sudden spike in that price (as was the case during the 2008 crisis). On the other hand, periods of higher demand for funding raise funding prices, potentially limiting the risk of overinvestment.

\section{ASSESSing Drivers of GLOBAL LIQUidity}

\section{A. Identification of Demand and Supply}

In order to identify changes in the demand and supply of liquidity, we use a vector autoregression (VAR) model with sign restrictions imposed (see Box 2 for more details on the methodology). ${ }^{15}$ Demand shocks are defined as parallel shifts of the (negatively sloped) demand curve with equilibrium prices and quantities moving in the same direction, ${ }^{16}$ In other words, a positive demand shock would be associated with a contemporaneous increase in both the price and quantity aggregate of liquidity.

Similarly, supply shocks are defined as parallel shifts in the (positively sloped) supply curve, with prices and quantities therefore moving in opposite directions. Thus, a positive supply shock would be associated with an increase in the quantity aggregate of liquidity, but a simultaneous decrease in the price.

Note that our usage reverses the convention regarding the demand and supply of money. Our supply of liquidity is the supply of funding, and corresponds to the demand for money in traditional monetary analysis. One advantage of this approach is that it focuses attention on the behavior of the financial sector and its balance sheet management over the cycle. ${ }^{17}$

In principle, our approach to identifying demand and supply makes no assumptions on the structure of the market for liquidity that is which institution or sector demand or supply liquidity. One can adopt the convention that the entity whose liabilities have increased following the transaction has demanded liquidity (funding), while the entity, whose assets have increased, has supplied liquidity.

\footnotetext{
${ }^{15}$ As suggested in Canova and De Nicolo (2002), sign restrictions can help identify supply and demand shocks. This approach has been widely used in the macroeconomic literature to identify business cycles (see also Uhlig, 2005; and Peersman, 2005).

${ }^{16}$ Krishnamurthy and Vissing-Jorgensen (2007) find evidence that demand curves for liquidity are negatively sloped, by studying the demand curves for liquidity services provided by Treasury debt.

${ }^{17} \mathrm{Kim}$, and others (2012), who also adopt this convention, argue that the "as if" preferences of the banking sector are more pro-cyclical than households, therefore there is a difference between e.g., households supplying credit via the financial sector as opposed to them directly investing in corporate bonds.
} 


\section{B. Historical Developments of Global Liquidity}

There are some noteworthy differences in the extent the dynamics of core and noncore global liquidity aggregates can be explained by the demands (pull) or supply (push) factors (Figures 6 and 7). ${ }^{18}$

In the case of core liquidity (Figure 6), it is possible to distinguish between three periods: (i) the brief period between 1999 and 2001 when positive liquidity supply shocks were outweighed by negative demand shocks, slowly reducing the available quantity of liquidity (as a ratio of GDP); (ii) the period when negative liquidity supply shocks brought the quantity of core liquidity well below trend by 2008, as investors were seeking more profitable investment instruments (e.g., money market funds, riskier assets); and (iii) the period during the global financing crisis when the positive liquidity demand and supply shocks kept core global liquidity above trend.

In the case of noncore global liquidity, one can distinguish between four periods (Figure 7):

(i) the first period when positive liquidity supply shocks allowed noncore liquidity (as a ratio to GDP) to trend upward, by remaining overall below trend; (ii) between 2005-07, when positive liquidity supply shocks contributed to rapid growth in noncore global liquidity, consistent with "inside" money creation, as global banks were able to create liquidity through a combination of leverage, financial innovation, and search for yield; (iii) during the global financial crisis, when the behavior of noncore liquidity was driven by a combination of falling supply, reflecting sudden retrenchment in wholesale markets, and rising demand, as banks needed funding to roll-over outstanding liabilities, the quantity of noncore liquidity remained stable, while its price increased sharply; and (iv) in 2011 onwards, when negative liquidity supply shocks depressed both the price and quantity of noncore liquidity, in line with the well-documented deleveraging in the shadow banking system.

It would be reasonable to conjecture that it was during the second period-between 2005 and 2007- that vulnerabilities started to build up, when financial innovation and other push factors allowed for an expansion of noncore liabilities, without a corresponding upward price pressure that could have served as a cooling mechanism (Figure 7). Poszar (2011), for example, argues that the increase in institutional cash pools (i.e., large centrally-managed short-term cash balances of global nonfinancial corporations and institutional investors) and their search for safe and liquid assets played an important role in the rise in the shadow banking system. ${ }^{19}$

\footnotetext{
${ }^{18}$ Note that the sum of the cumulative contributions from demand and supply factors does not add up to the total quantity level, due to the persistent contributions of supply and demand shocks that have occurred prior to the start of the sample.

${ }^{19}$ Poszar (2011) argues that yield was only the third priority for this set of investors, liquidity and safety of the principal being the more important considerations.
} 
In our framework, it is the combination of a rising quantity and subdued price movements that indicate a rising vulnerability in the form of excess supply (push) factors. Hahm and others (2011) argue that a large stock of noncore liabilities can indicate an erosion of risk premiums and hence a possible crisis vulnerability. This is also consistent with Bruno and Shin (2011), who argue that as long as global banks do not internalize the marginal price of an increase in funding, they will increase their liabilities to finance additional lending.

\section{Historical Developments of Core and Noncore Liquidity by Country}

Applying the same approach as above, it is possible to decompose the dynamics of liquidity at the regional level, with some interesting differences between U.S., the euro area, Japan and the United Kingdom.

In the United States and the euro area, the dynamics of core liquidity were largely demanddriven. In the United States, the demand for core liquidity (relative to trend) fell in the run-up to the crisis, as banks were increasingly shifting to wholesale markets as a source of funding. It rose sharply during the height of the global financial crisis in 2008, as alternative funding markets dried up. Since then, it started to fall again, reflecting perhaps deteriorating fundamentals or expectations. In contrast, in the euro area, the contribution of core liquidity demand shocks remained positive throughout the precrisis period, peaking at the onset of the global financial crisis in 2008. Since then, the demand for core liquidity has fallen, possibly reflecting weak fundamentals and banks' ability to rely on official funding markets.

In the United Kingdom, core liquidity dynamics before the crisis were driven largely by supply factors. As in the United States and the euro area, strong demand shocks characterized the global financial crisis, first positive (as wholesale markets dried up), then turning negative (as the levels of economic activity declined).

Japan followed an overall different pattern. Partly, this can be explained by the fact that it is the only economy in the G4 sample that experienced falling nominal GDP throughout the sample. Thus, after experiencing a progressive fall since early 2000 , driven primarily by liquidity supply factors, the ratio of core liquidity to GDP in Japan (relative to trend) rose sharply at the onset of the global financial crisis, reaching record high levels by end-2011. The increase was also supply driven, possibly also reflecting a substitution away from noncore to core funding (Figure 2).

A simple review of pairwise correlations between quantity and price measures for different countries supports the view that developments in the core liquidity are more dependent on country-specific factors, whereas noncore liquidity developments are more global in nature. Excluding Japan ${ }^{20}$ from the sample, the average pairwise correlation coefficient for quantity

\footnotetext{
${ }^{20}$ Japan has distinctly different dynamics for both core and noncore liquidity, but especially for noncore. In part, this is explained by the different path of the nominal GDP—our normalizing variable.
} 
series of core liquidity is 0.51 ( 0.71 for noncore liquidity), and -0.08 for the price measure of core liquidity ( 0.71 for the price measure of noncore liquidity).

Country-specific dynamics of noncore liabilities are presented in Figures 8 and 9. The historical decomposition for each of the G4 economies suggests that the rise in noncore liabilities was largely a supply phenomenon in the United States-reflecting possibly structural factors in intermediation, including the highly pro-cyclical collateral-based "inside money" creation associated with the proliferation of structured products (Figure 8). This supply phenomenon, however, was fueled by strong demand for noncore liabilities in the United Kingdom, and to a lesser extent in the euro area. This is consistent with global banks using their United States branches and subsidiaries to fund purchases elsewhere. Bruno and Shin (2011), for example, argue that European banks played a key role in providing U.S. dollar intermediation - raising wholesale funds in the United States and reinvesting in U.S. asset-backed securities (ABS) or channeling these funds to other regions.

\section{Historical Developments in Countries' External Liabilities to Banks}

The historical decomposition of G4 external liabilities to BIS reporting banks is shown in Figure 10. Using the same price index to proxy the price of BIS external liabilities, we find that the behavior of G4-based noncore global liabilities is very similar to that of the G4 external liabilities to BIS reporting banks (Figure 7). This suggests a close link between noncore global liquidity and cross-border funding by global banks or confirming that global banks are at the heart of transmitting noncore global liquidity across the world.

Assuming that this close link applies also to non-G4 countries, we construct the same historical decomposition for the external liabilities of other countries to BIS reporting banks (Figure 11). There are some indicative differences: firstly, much of the trend in external liabilities is demand-driven. Secondly, there is a much more dramatic fall relative to the trend during the crisis of 2008 , followed by a speedy recovery and a gradual reversion to trend (Figure 4). While part of this volatility is driven by changes in nominal GDP, this seems to suggest that the deleveraging process in the G4 countries has been more prolonged than in other countries, including those with stronger economic prospects (e.g., Australia, Canada, and Korea).

\section{The REAL IMPACT OF GLOBAL LiQUidity}

We use two approaches to study the real impact of global liquidity on growth. First, a panel regression (PR) studies the differing impact of global liquidity shocks - core and noncoreon economic growth over time (Box 3). Second, a vector-autoregression (VAR) model estimates the country-specific impact of shocks to global liquidity (Box 4). Together, these two approaches provide a comprehensive picture of the real impact of global liquidity. In 
particular, while the PR approach highlights the average impact across a group of countries, the VAR focuses on individual country dynamics.

For our analysis, we use unbalanced panel data, covering a set of emerging and advanced economies for the period from the first quarter of 1999 to the first quarter of 2011. The sample period reflects data availability for global liquidity aggregates. The countries include the following:

- “G4" economies, including: Japan, the United States, United Kingdom and the euro area, collectively referred as G4 in the paper;

- Other European countries, including Bulgaria, Croatia, Czech Republic, Denmark, Estonia, Iceland, Israel, Latvia, Lithuania, Norway, Poland, Romania, Russia Switzerland, and Sweden;

- Other Asian economies, including Australia, China, Hong Kong SAR, India, Indonesia, Korea, Malaysia, New Zealand, Pakistan, Philippines, Singapore, Sri Lanka, Thailand and Vietnam;

- Other Western Hemisphere countries, Argentina, Brazil, Canada, Chile, Colombia, Mexico, and Peru;

- “Other" economies, including Nigeria, Saudi Arabia, South Africa, and Turkey.

The key results of the PR regressions are presented in Table 2, with a range of robustness tests presented in Tables 3-4. The VAR results associated with demand and supply shocks on core liquidity are presented in Figures 12 and 13, while Figures 14 and 15 illustrate the GDP response from demand and supply shocks on noncore liquidity.

Our analysis sheds light on a number of stylized facts regarding the feedback effects between global liquidity and real GDP growth. Overall, we find that the types of funding shockswhether through core (bank based) or noncore (collateral based), and more specifically, whether they are supply- or demand-driven, matter. And, our results suggest that the financial crisis may have altered the dynamics between liquidity shocks on growth.

- The results show that demand shocks to liquidity have stronger effects on real GDP than supply shocks. This is particularly striking in the case of demand shock to noncore liquidity, which has not only the largest negative impact within the G4 economies, but also the largest spillover to other advanced markets (Figure 15). ${ }^{21}$ In particular, the average impact of a one standard deviation shock rises to

\footnotetext{
${ }^{21}$ It is also the case with the largest number of countries for which the confidence interval does not include zero.
} 
-0.98 percentage points of GDP after eight quarters ( -0.90 percentage points of GDP for the non-G4 countries).

- The results suggest that demand-driven shocks have long-lasting results, while supply-driven shocks tend to fade by eight quarters. For example, while demand shock to noncore liquidity reduce real GDP by up to 0.98 percentage points over eight quarters, the real impact of supply shocks falls to 0.18 percentage points over the same time frame. This result is true both for G4 economies and the other economies, except for demand shocks for core liquidity, which seem to have limited spillover effects. This result reflects the domestic nature of core liquidity.

- $\quad$ Furthermore, we find that both demand and supply shocks to core liquidity are counter-cyclical. A positive demand (supply) shock to core liquidity lowers real GDP by 0.5 (0.3) percentage points after eight quarters (Figure 12). This is consistent with the idea that a rise in core liquidity is associated with a "flight-to-safety" behavior on the supply side or limited alternative funding sources on the demand side, both of which tend to occur under worsening economic conditions. Furthermore, rising funding costs are likely to spur further deleveraging, leading to further adverse growth effects. In contrast, we find that positive supply shocks to noncore yield a positive impact on GDP growth, in line with the idea of "inside" money creation through leverage and financial innovation, as witnessed during the run-up to the global financial crisis with the explosion of noncore liquidity (Figure 14).

- Our analysis offers a number of nuances (Table 3). First, the ranking of the relative GDP impact of different shocks is slightly different, with supply (rather than demand) shocks to noncore liquidity yielding the largest positive impact on GDP growth. This result would be consistent with the idea that noncore liquidity shocks reflect "inside" money creation, as banks raise funding in wholesale markets to leverage and expand their balance sheets, with such balance sheet expansions occurring typically around economic expansions. Second, under the panel regression analysis, supply shocks to core liquidity have a positive (rather than negative) impact on GDP growth over the entire sample, although the impact is reversed during the crisis, when it becomes strongly negative. The difference between the panel regression results (Table 3 ) and the VAR (Figure 12) may be due to an important difference between the two methodologies: The panel regression provides more robust estimates of the unconditional average instantaneous effects of supply and demand shocks, whereas the VAR results focus in the effects of shocks over time and after taking into account their effects on other variables included in the VAR (e.g., inflation).

- Our analysis provides also some interesting results about the changing nature of funding shocks on growth over time. First, we find that the strongly positive impact of noncore liquidity supply shocks was driven largely by the precrisis period (Table 4). During the global financial crisis, the impact of liquidity on GDP was negative, 
driven primarily by (demand and supply) shocks to core liquidity. This suggests that core liquidity was rising (relative to GDP) as a result of deteriorating fundamentals and rising risk aversion, rather than, say, price pressures. In the post-crisis, however, the impact of liquidity on GDP turned positive again, primarily driven by demand shocks to core liquidity and, to a lesser extent, noncore liquidity, in line with a resumption of economic activity and more normal credit transmission mechanisms. The higher post-crisis demand for core liquidity reflects partly recent regulatory reforms that encourage greater reliance on core funding (e.g., Basel III liquidity requirements, Dodd-Frank Act in the United States, Capital Requirement Directive IV in Europe).

- Lastly, the results show that demand shocks to noncore liquidity on growth are counter-cyclical while supply shocks are pro-cyclical. The explanation for the growth effect of a positive supply shock is intuitive, as greater availability of funding at a lower cost allows banks to expand the asset side of their balance sheet and correspondingly provide more credit to the real economy. The negative effect of demand shocks may be attributable to the lagged nature of deleveraging. One scenario in which this may occur took place during the 2008 financial crisis when falling collateral prices forced financial institutions to reduce their balance sheet (i.e., to deleverage), while the availability of noncore funding fell sharply. Tightened financing conditions, in turn, further depressed GDP, exacerbating macro-financial linkages.

- The analysis suggests no statistically significant cross-country variations in the sensitivity to G4 funding shocks.

\section{Conclusion}

Recent history has highlighted the impact of liquidity on financial and economic stability. The task of measuring and monitoring liquidity, however, is complicated by the fact that liquidity is endogenous and cyclical. By using quantity and price measures, we are able to better assess developments in liquidity conditions. Moreover, the interaction of price and quantity allows us to determine supply and demand-driven shocks underlying liquidity changes. Our preliminary work suggests that both core and noncore liabilities and the nature of the shocks - demand or supply-driven - have important effects on growth. From a surveillance perspective, our work confirms the importance of capturing liquidity creation from both traditional bank channels and the more volatile nonbank channels.

Notably, depending on the economic cycle, quantity and price information can capture different developments. The interaction between price and quantity of liquidity help to identify drivers of liquidity expansion - above the rate suggested by nominal GDP growthas demand, or supply based. A positive demand shock would result in an increase in quantity, accompanied by a rise in price, while a positive supply shock would result in an increase in 
quantity, but a decline in price. It is the protracted periods of low prices seen in the latter scenario - a result of positive supply shocks - that can raise risks to financial and economic stability. Moreover, while quantities are sticky in a downward adjustment, changes in prices may be more telling in a crisis. Thus, disentangling supply and demand factors behind price and quantity indicators can provide a richer framework for analysis.

More specifically, the types of shocks on liquidity matter for growth. We find that shocks to noncore liquidity tend to have a stronger effect relative to core liquidity. This likely reflects the fact that noncore liquidity creation is highly endogenous to the economic cycle, expanding through leverage and balance sheet growth with lower prices, and correspondingly, fueling perceptions of lower risks and even greater leverage. In particular, the perception of risk (as reflected by the price of funding) may be at its lowest when risk exposures (as reflected by financial sector liabilities) are highest. The impact of a negative shock to noncore liquidity can therefore be sizeable as market participants delever and reduce balance sheet exposures.

In addition, we find that the source of liquidity shocks - whether demand or supply-driven matter. Supply shocks to noncore liquidity are procyclical to growth; this is intuitive: greater liquidity creation and balance sheet expansion boost economic activities. Meanwhile, demand shocks are countercyclical to growth. The intuition here is best explained by the stabilizing effect of demand-driven increases in liquidity: as prices rise, the cost of funding increases accordingly, dampening demand and correspondingly, balance sheet expansion. Thus, the ability to interpret liquidity developments in terms of supply and demand is important for monitoring both the price and quantity of liquidity and the underlying financial and economic conditions.

This work points to a number of notable further areas of work. In particular, the identification of supply and demand hinges on the accuracy of the price indicators, which can be difficult to establish. Furthermore, more work is needed to establish the properties of global liquidity, including the role of structural breaks and financial innovation.

Ultimately, there is no simple "cookbook" for understanding country responses to shocks to global liquidity - which will depend, among other things, on structure of the financial sector, openness, monetary autonomy, etc. Likewise, at the global level, policy responses to liquidity shocks will depend on the specifics and origin of the shock. In general, Goodhart's Law reminds us of the futility of pursuing any particular monetary aggregate or indicator-as behavior of actors change, these can quickly lose whatever forecasting value they once had. Still, trying to understand supply and demand developments in funding markets can provide important information. 


\section{Box 1. Estimation of the Noncore Liquidity Price Index}

The dynamic factor model (DFM) for the noncore liquidity price index assumes each standardized monthly financial indicator $\left(y_{t}\right)$ can be decomposed into a common component $\left(\gamma F_{t}\right)$ and an idiosyncratic component $\left(\varepsilon_{t}\right)$, such that

$$
y_{t}=\gamma F_{t}+\varepsilon_{t}, \quad \text { where } \varepsilon_{t} \sim N(0, \varphi)
$$

where $\varphi$ is assumed to be diagonal, which implies that idiosyncratic components are uncorrelated across indicators. The common factor $\left(F_{t}\right)$ is our estimated noncore liquidity price index (NLPI), which is assumed to follow an autoregressive (AR) $p$ process:

$$
F_{t}=\sum_{i=1}^{p} \beta_{i} F_{t-i}+\omega_{t}, \quad \text { where } \omega_{t} \sim N(0,1)
$$

where $\beta_{i}$ 's are the AR coefficients and $\omega_{t}$ is a normally distributed error term. The lag length $p$ is selected using the Swartz-Bayesian information criteria. Given that the common factor is unobserved, we estimate the above State-space system using the Kalman filter.

The estimated NLPI is a weighted average of our chosen set of financial indicators, where the weights are optimally determined by the Kalman filter recursion. The Kalman filter allows accommodating mixed frequencies and uneven sample lengths (e.g., in the case of bank lending surveys). The indicators include variables such as interest rate spreads, asset prices, risk appetite, and lending condition surveys (Matheson, 2011). For missing data, "back-casting" is used to complete the series using the methodology of Giannone, Reichlin, and Small (2008). The global NLPI is constructed by pooling the G4 indicators. 


\section{Box 2. Indentifying Demand and Supply Shocks}

First, we consider the presence of trends in our price and quantity measures of global liquidity. According to the (two standard) augmented Dickey-Fuller (ADF) and Phillips-Perron unit root tests, the quantity indicators of global liquidity (both expressed as a ratio to GDP and in U.S. dollars) contain a unit root, Thus, one can decompose the quantity indicators into a trend and cycle component. The trend growth of Noncore and core liabilities as a ratio to GDP is 1 percentage point and half a point per quarter, respectively. Deviations from trend are persistent. Thus, by assuming a linear trend, all stochastic variation in the quantity series is interpreted as persistent supply and demand shocks.

Next, a vector auto-regression (VAR) model is used to identify the demand and supply shocks to global liquidity using the sign restriction approach. After regressing the de-trended quantity and price indicators of global liquidity on their lagged values using quarterly data from 1999Q1 to 2011Q1, it is possible to identify supply and demand shocks using sign restrictions. Initially, one can consider an unrestricted VAR model:

$$
x_{t}=c+B(L) x_{t-1}+\varepsilon_{t},
$$

where $x_{\mathrm{t}}$ is a vector containing both the price and quantity measures of global liquidity at time $\mathrm{t}$, $B$ is the matrix polynomial in lags with an order $p$ (based on Bayesian Information Criterion), and $\varepsilon_{\mathrm{t}}$ is a vector of reduced form residuals assumed to be normally distributed with mean zero and covariance matrix $\Omega$. Using the Cholesky decomposition, it is possible to convert equation (1) into a structural model with a diagonal covariance matrix.

$$
(P Q)^{-1} x_{t}=(P Q)^{-1} c+(P Q)^{-1} B(L) x_{t-1}+u_{t},
$$

where $\mathrm{P}$ is matrix such that $\mathrm{PP}^{\prime}=\mathbb{B}, \mathrm{Q}$ is an orthonormal matrix, ${ }^{5} u_{t}$ are structural residuals with identity matrix as the covariance matrix.

Because different rotations of the matrix P (or different values of Q) yield observationally the same values of the likelihood functions, it is possible to choose the specification whose impulse responses match the sign restrictions. Also, to limit the choice of models to a particular range of magnate impulse responses, this paper uses the "median targeting" approach, which picks the median impulse response among a large number of iterations. ${ }^{1}$

Having identified individual supply and demand shocks, one can use a World historical decomposition procedure to identify cumulative contributions of supply and demand shocks (see, for example, Kilian, 2009, for decomposing oil demand and supply factors). Thus, after choosing a particular model which matches the sign restrictions, historical decomposition rewrites (2) as:

$$
y_{t}=a+\Psi_{1} \epsilon_{\mathrm{t}}^{\mathrm{d}}+\cdots+\Psi_{\infty} \epsilon_{\mathrm{t}-\infty}^{\mathrm{d}}+\Pi_{1} \epsilon_{\mathrm{t}}^{\mathrm{s}}+\cdots+\Pi_{\infty} \epsilon_{\mathrm{t}-\infty}^{\mathrm{s}},
$$

with $y_{t}$ is decomposed into current and past structural demand $\left(\epsilon_{\mathrm{t}}^{\mathrm{d}}\right)$ and supply $\left(\epsilon_{\mathrm{t}}^{\mathrm{s}}\right)$ shocks.

\footnotetext{
${ }^{1}$ The small sample size limits the estimation to a time invariant VAR. The minimum number of models is between 3,000 or the number such that the difference between the median responses of two sets of models is reasonably small (see also Fry and Pagan (2010) for details).
} 


\section{Box 3. A Panel Regression Approach to Assessing the Real Impact of Global Liquidity}

In order to assess the impact of liquidity on growth, we use two groups of explanatory variables in the specifications: macroeconomic variables that include country policy rates and inflation, and the supply and demand shocks to global liquidity as identified in Box 2.

$$
y_{t}=\beta_{1} y_{t-1}+\beta_{2} R_{t-1}+\beta_{3} P_{t}+\beta_{4} C S_{t-1}+\beta_{5} C D_{t-1}+\beta_{6} N C S_{t-1}+\beta_{7} N C D_{t-1}+\varepsilon_{t}
$$

Where

$y$ is the real growth rate, on a year on year basis,

$\mathrm{R}$ is the country policy rate,

$\mathrm{P}$ is country headline inflation, year on year,

CS is supply shock on core liquidity,

$\mathrm{CD}$ is demand shock on core liquidity,

NCS is supply shock on noncore liquidity,

NCD is demand shock on noncore liquidity

The PR approach uses a two-step Arellano-Bond GMM estimator to address several econometric problems that could arise from the equation. First, the global liquidity variablescore and noncore liquidity as well as the supply and demand shocks - is assumed to be endogenous, while inflation and policy rates are considered as predetermined. Furthermore, because causality may run in both directions, they may be correlated with the error term. Second, the presence of lagged dependent variable gives rise to autocorrelation. Thus, the specification is instrumented using up to one lag. Lastly, time-invariant country characteristics (fixed effects) - e.g., demographics or geography — may be correlated with the explanatory variables.

A number of additional variables were introduced to control for the behavior of global liquidity. To explore cross-country variations in the sensitivity to funding shocks, a G4 dummy variable is introduced, which takes on the value of 1 if the country is a part the euro area, Japan, U.K. and the U.S and zero otherwise. To assess whether the financial crisis altered the impact of liquidity shocks on growth, we also introduced a crisis dummy variable, which takes on the value 1 if observations occur between the period of Q4 2007 and Q2 2009, as per NBER U.S. recession dating and zero otherwise. To assess the possibility of lingering effect of the crisis on the interaction between funding shocks and growth, even after the resumption of growth and credit intermediation, we introduced a post-crisis dummy, which equals to 1 for the period following the financial crisis and zero otherwise. 


\section{Box 4. A VAR Approach to Assessing the Real Impact of Global Liquidity}

To explore the real economy impact of liquidity shocks, we use a VAR model similar to (1). We restrict our attention to the cumulative impulse response functions of real GDP growth rate over two, four and eight quarter horizons. These cumulative impulse responses are close approximations of the level changes in real GDP following a shock to global liquidity. The impulse responses of variable $i$ to a one standard deviation shock in variable $j$ are computed from (2) as:

$$
\operatorname{IR}(i, j, t)=q \Gamma^{\mathrm{t}} \mathrm{As}^{\prime}
$$

where $q$ and $s$ are the selection vectors of appropriate size with 1 in the $i$-th and $j$-th elements and all other elements set to zero, $\Gamma$ is the companion matrix of the VAR and $A=P Q$ from Section IV. To establish confidence intervals around the estimates of impulse responses, we follow the approach based on the bootstrap confidence intervals with adjustments for small sample sizes as proposed by Kilian (1998). ${ }^{1}$ First, we collect the estimates of the VAR coefficients into a single vector $\hat{\beta}=\operatorname{vec}(B(L))$. Randomly resampling (with replacement) the residuals from the original estimation and simulating the process with the estimated coefficients $\hat{\beta}$ allows obtaining a thousand of additional samples and coefficient estimates. Denoting the average of these additional coefficient estimates by $\beta^{*}$ allows estimating the bias of the bootstrap procedure as suggested by Kilian (1998):

$$
\Delta=\beta^{*}-\hat{\beta}
$$

Such an approximation for bias is accurate to the first order and amounts to assuming that the OLS bias in regressions that include lagged dependent variable is constant in the neighborhood of $\hat{\beta}$. One can now proceed to construct the bias corrected estimate $\tilde{\beta}$ of the true model parameters $\beta$ as follows: if all of the eigenvalues of the companion matrix associated with $\hat{\beta}$ are inside the unit circle, the bias corrected estimate is constructed as $\widetilde{\beta}=\hat{\beta}-\Delta$, otherwise set $\tilde{\beta}=\hat{\beta}$. If any of the eigenvalues of the companion matrix associated with $\widetilde{\beta}$ are outside the unit circle, one can further let $\delta_{1}=1$ and $\Delta_{1}=\Delta$ and define $\Delta_{i+j}=\delta_{j} \Delta$ and $\delta_{j+1}=\delta_{j}-0.01$. One can then iterate these equations and set $\tilde{\beta}=\hat{\beta}-\Delta_{\mathrm{i}+\mathrm{j}}$ for $j=1,2, \ldots$ until all of the eigenvalues associated with the companion matrix with coefficients $\tilde{\beta}$ are inside the unit circle.

The second and final step of the algorithm involves using $\tilde{\beta}$ to generate further additional bootstrap samples, correcting them for bias and possible nonstationarity as above and hence obtaining the bias-corrected 90 percent confidence interval (using the 5-th and 95-th percentile of the bootstrap distribution of cumulative impulse responses) as well as the median estimate. The resulting confidence intervals of the impact of a one standard deviation shock to the supply or demand of core and noncore liquidity are summarized in Figures 12 through 15.

\footnotetext{
${ }^{1}$ Other possible approaches include Monte Carlo integration methods, although our small sample size is a big limitation, and
} asymptotically valid confidence intervals, which uses a Bayesian (rather than frequent) approach. 
Chart 1: Stylized Representation of Core and Noncore Linkages

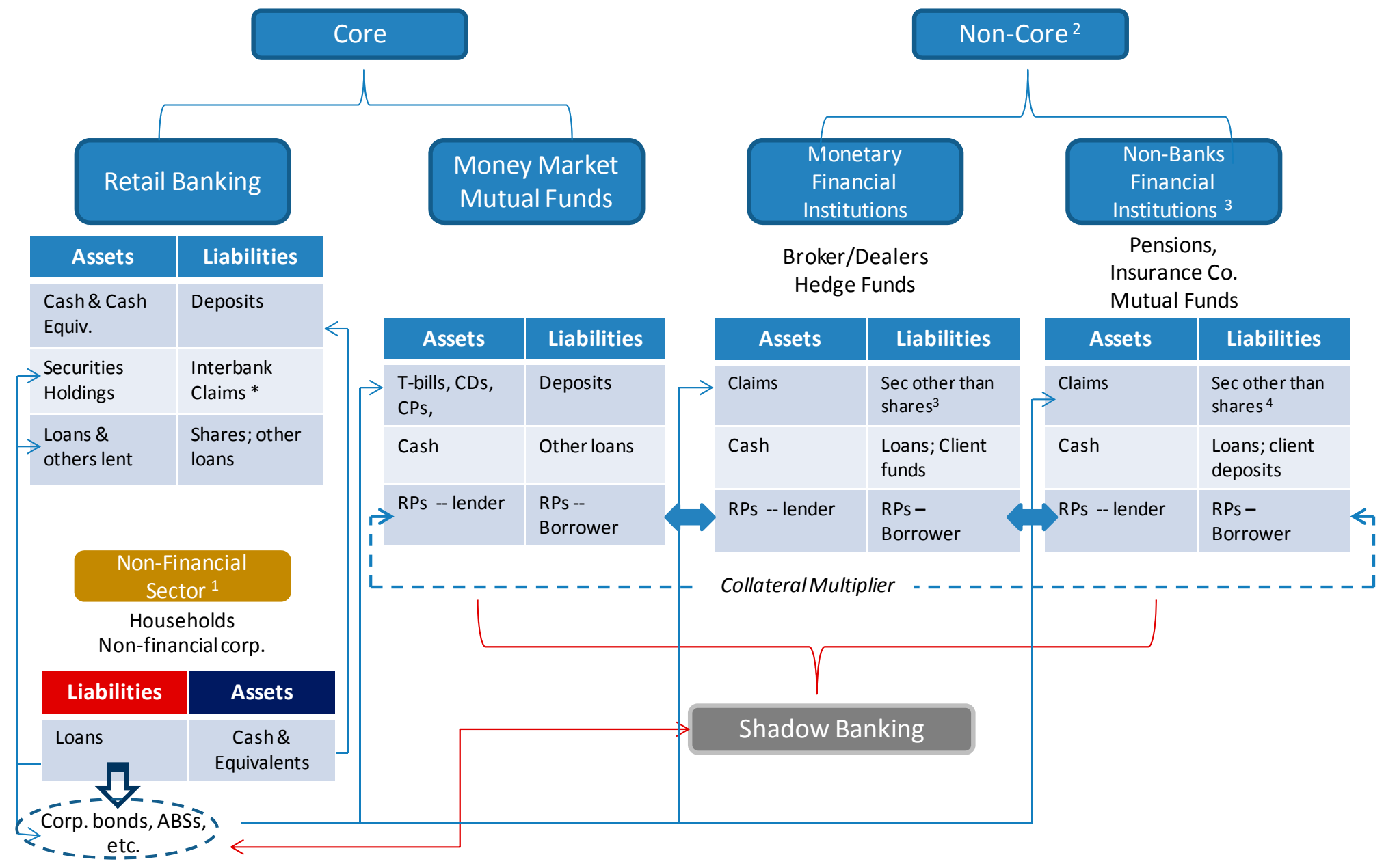

*Interbank claims are not included in core estimates

${ }^{1}$ Nonfinancial sector includes domestic households and nonfinancial corporations;

${ }^{2}$ Noncore financial institutions generally accept long-term or specialized types of deposits and issue securities and equity.

Noncore liquidity also includes loan and securities (other than shares) of commercial banks.

${ }^{3}$ Examples of nonbanks financial institutions, in addition to the ones listed above, include investment pools and vehicle companies.

${ }^{4}$ Securities other than shares may include CPs, CDs. MBS and credit card and loan receivables. 
Figure 1. Total G4 Liquidity in Trillion Dollars and As a Ratio to GDP
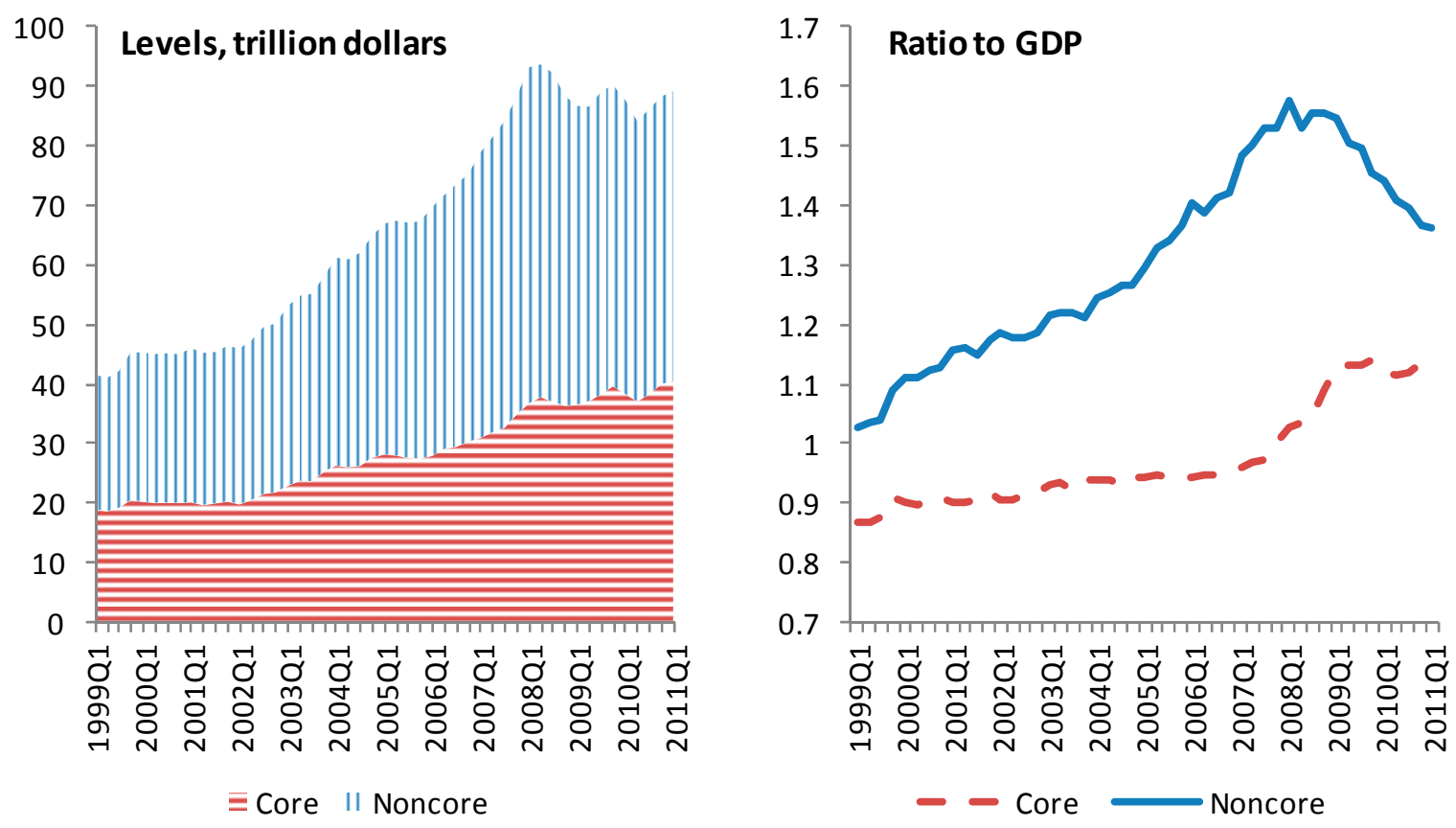

Sources: Haver and Fund Staff calculations.

Figure 2. National Measures of the Quantity of Liquidity, Ratio to National Nominal GDP
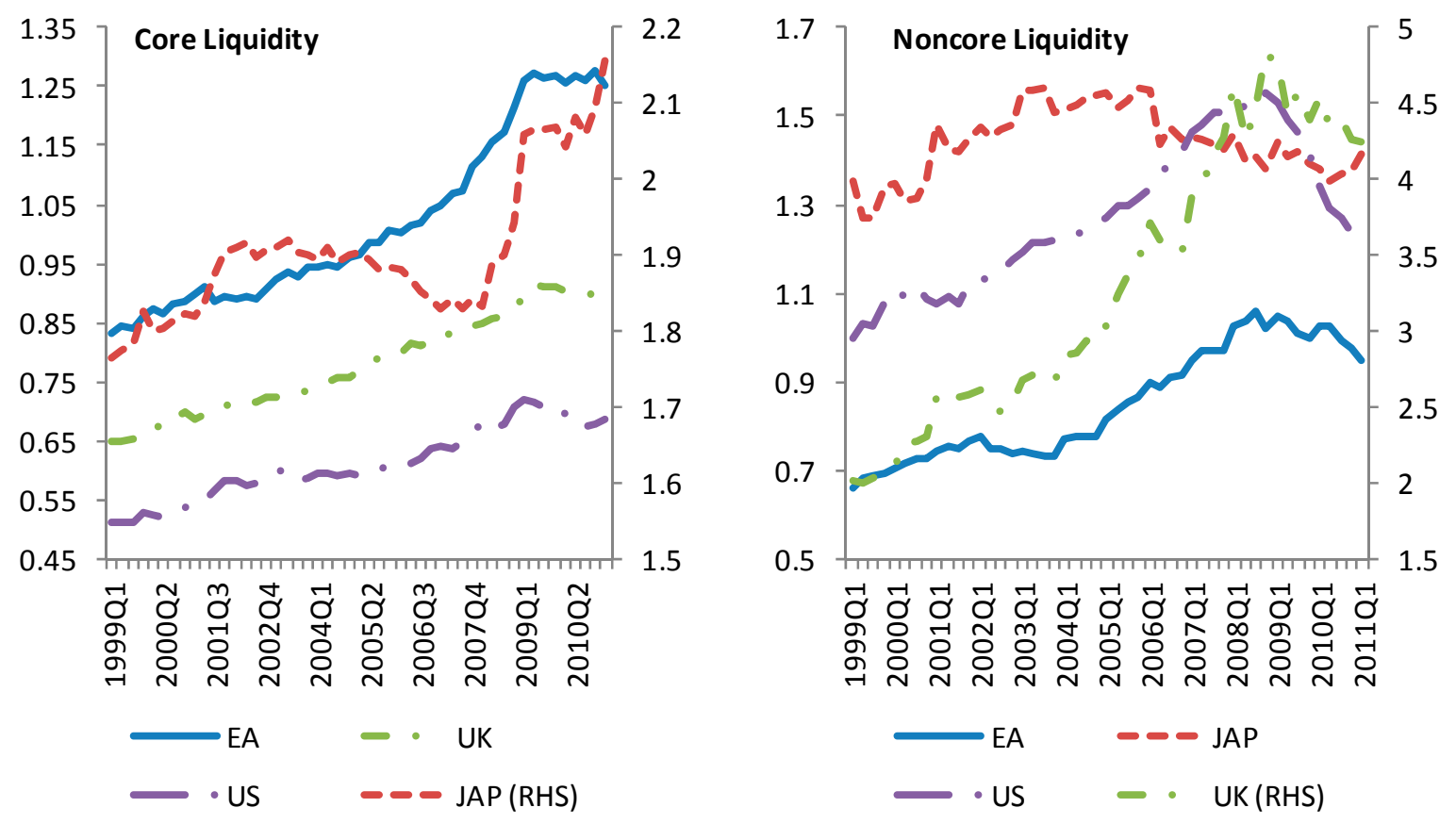

Sources: Haver and Fund Staff calculations. 
Figure 3. National Measures of the Quantity of Liquidity, Trillion US dollars 1/
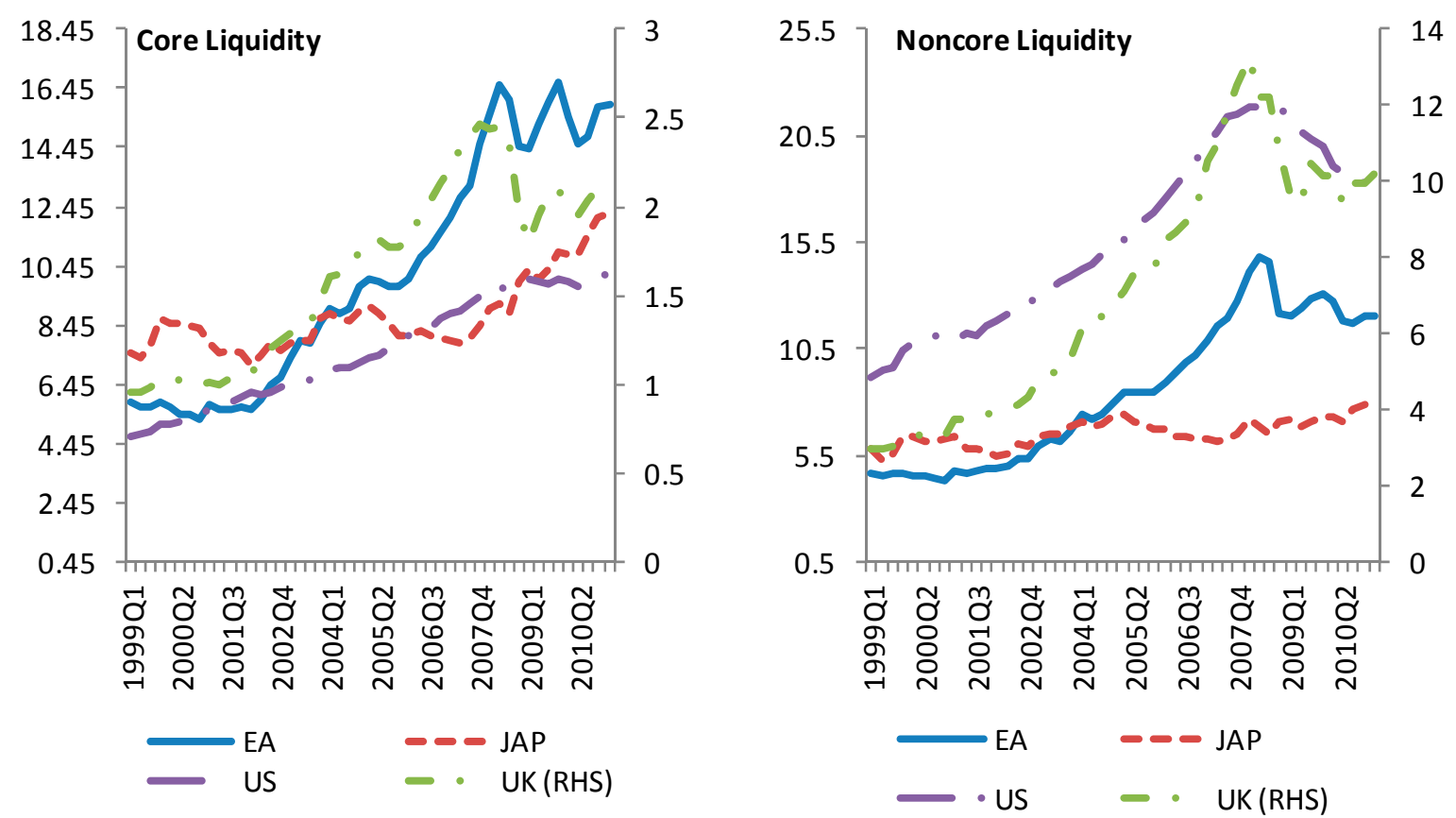

1/ At market exchange rates.

Figure 4. Total External Liabilities to BIS Reporting Banks
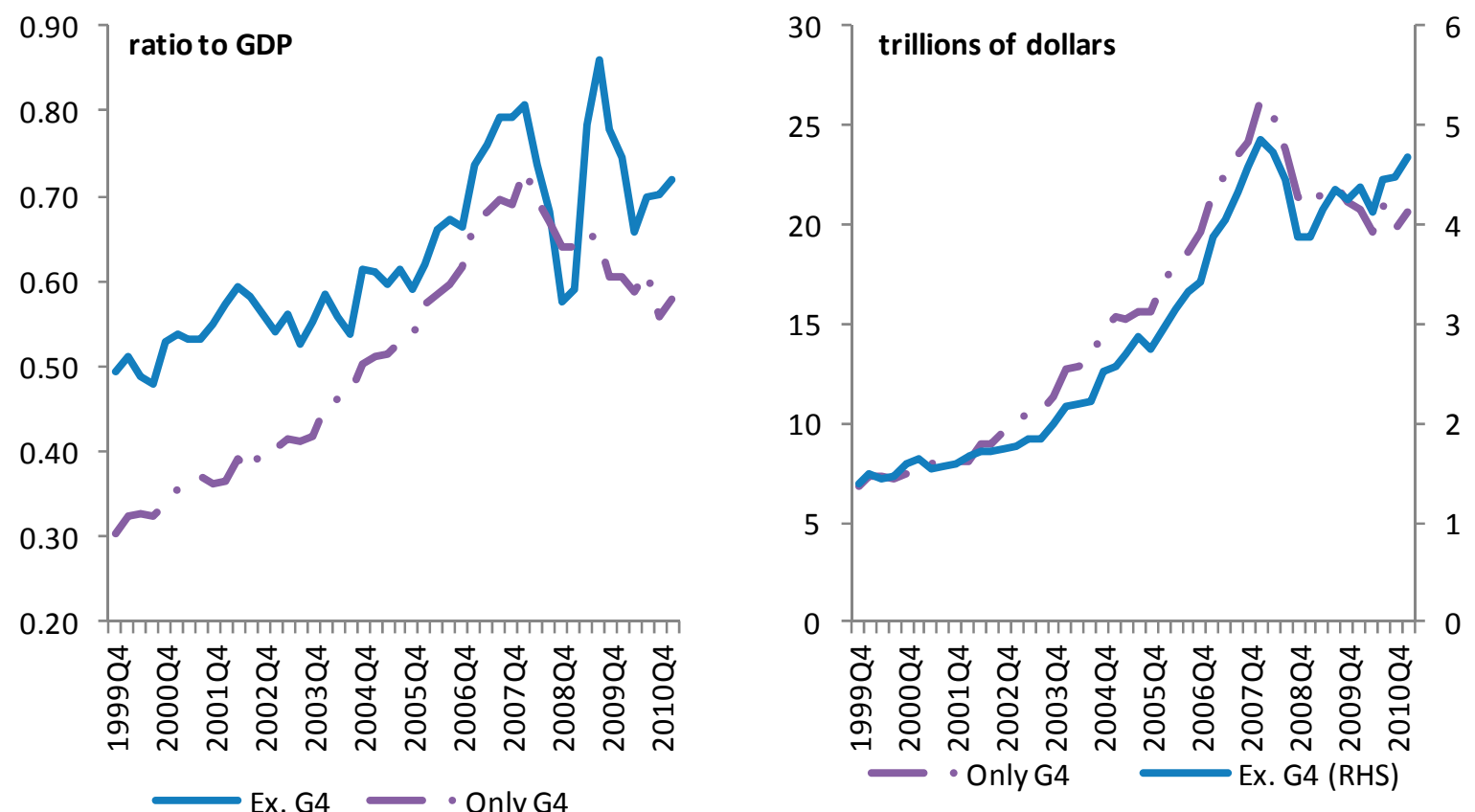
Figure 5. Nominal GDP Growth Rates, q. on q.

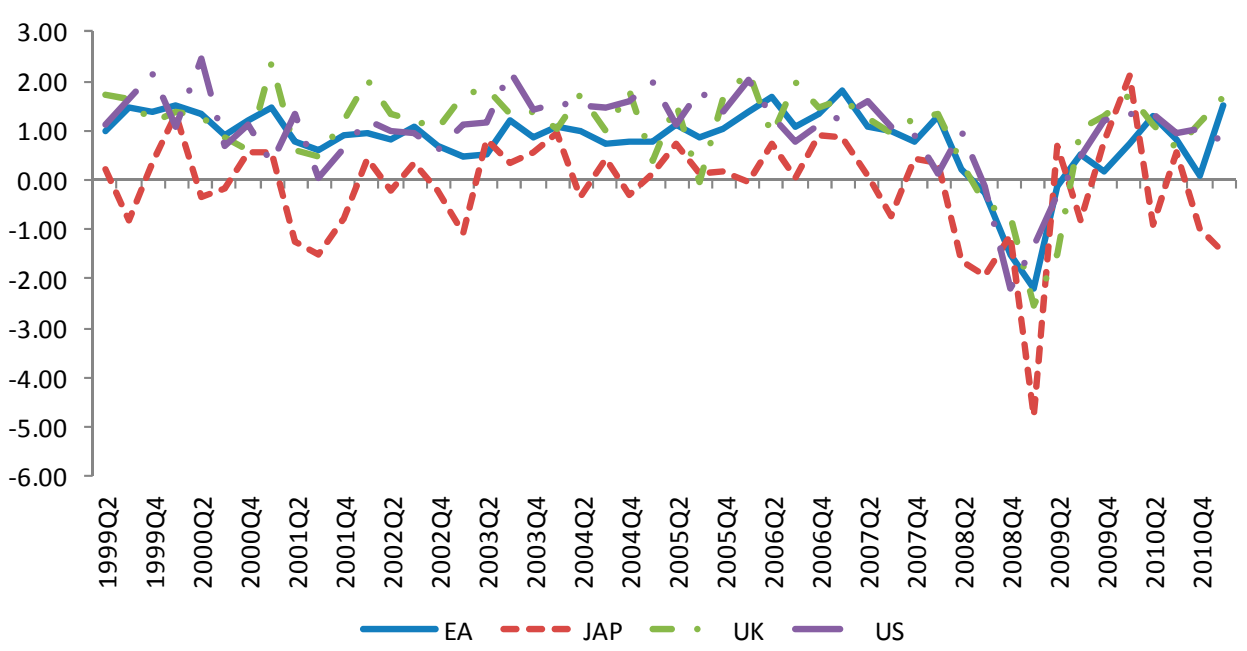

Figure 6. Supply and Demand Shocks, Quantity and Price of Core Global Liquidity

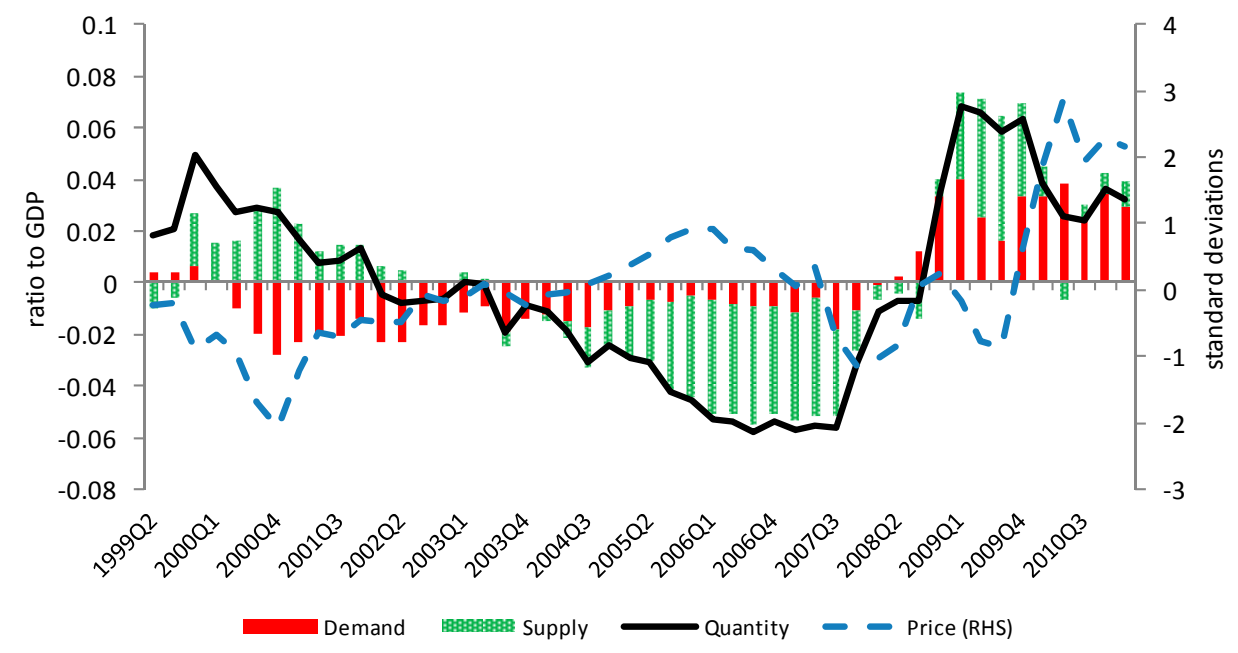

Figure 7. Supply and Demand Shocks, Quantity and Price of Noncore Global Liquidity

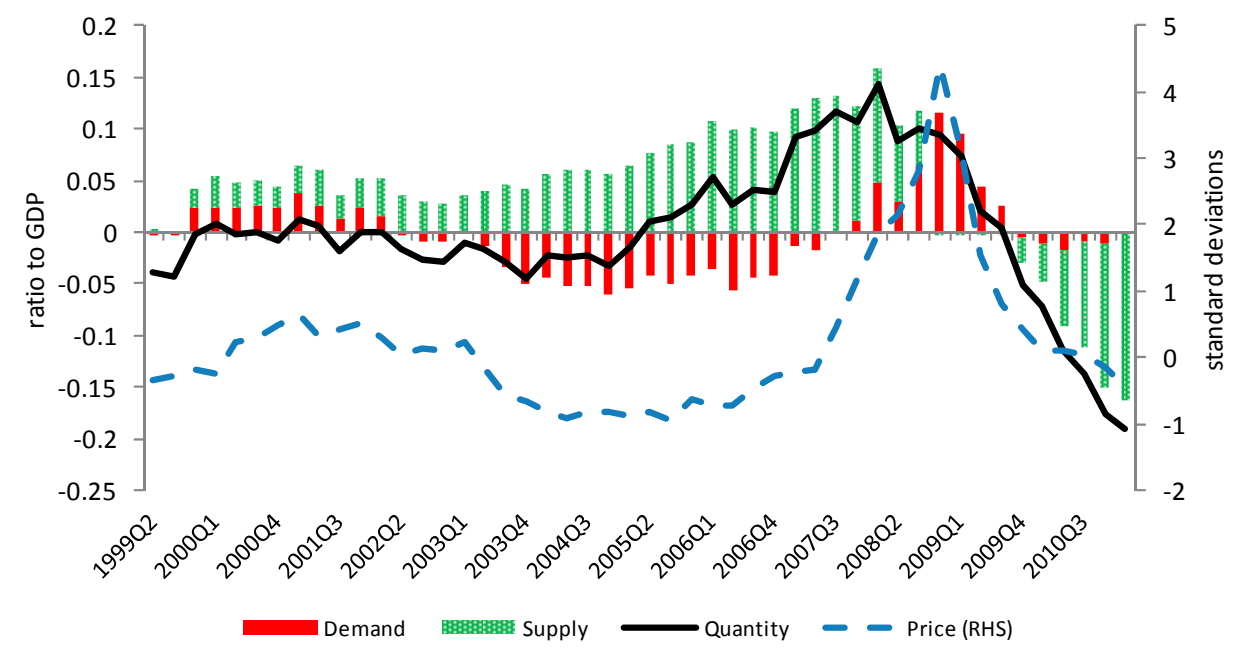


Figure 8. Supply and Demand Shocks, Quantity (ratio to GDP) and Price (standard deviations) of National Liquidity Aggregates

United States
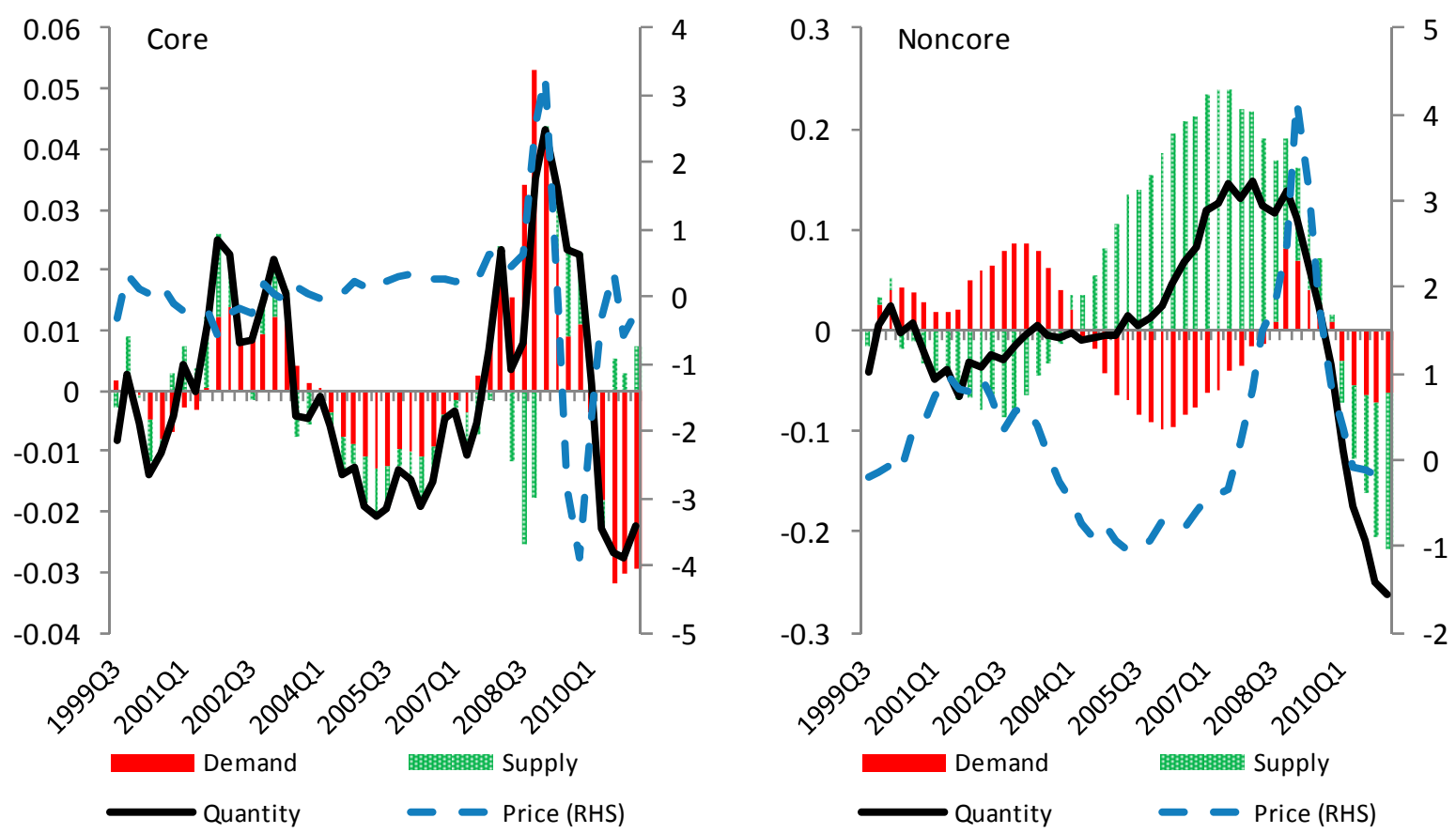

\section{Euro Area}
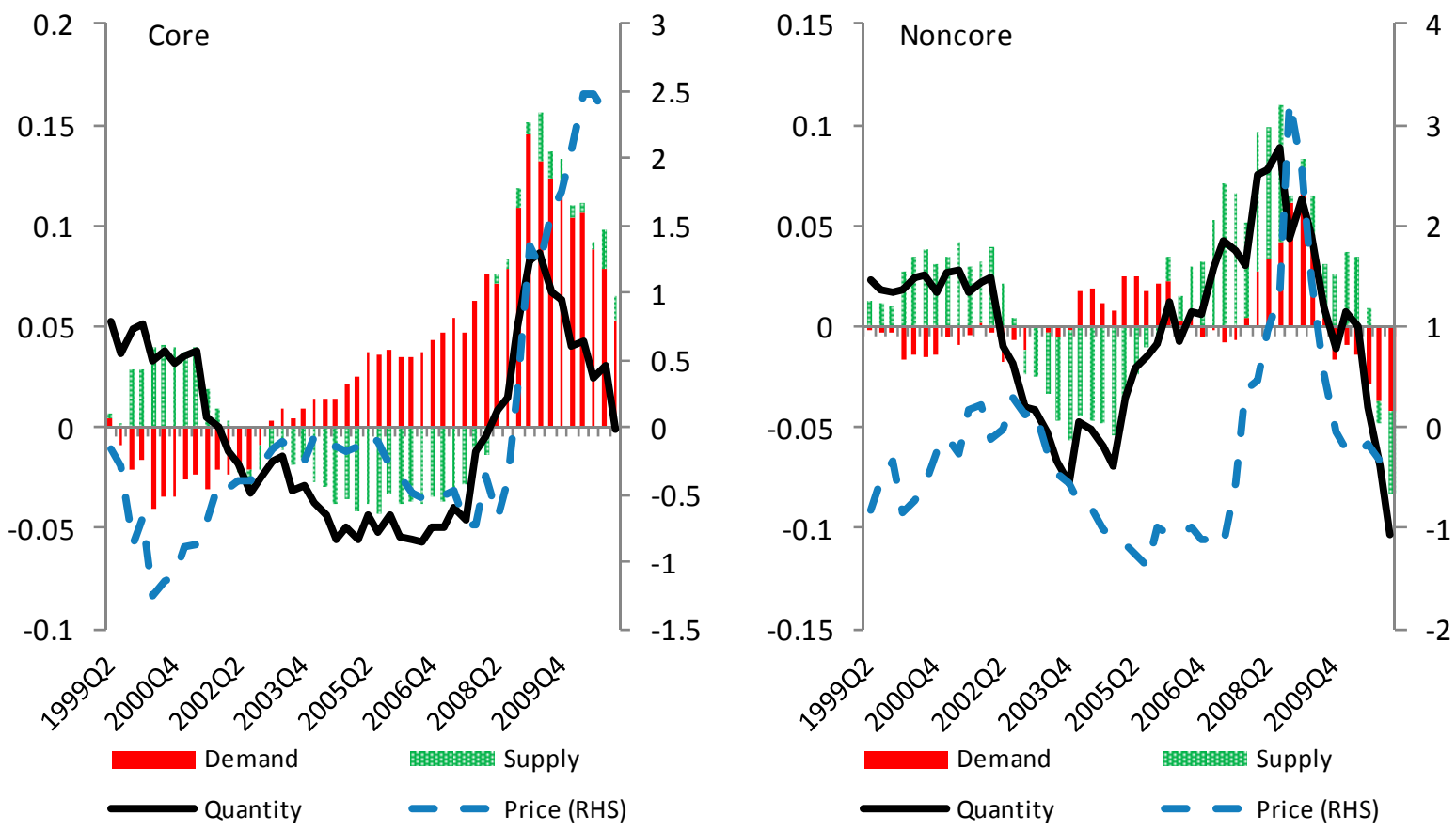
Figure 9. Supply Demand Decomposition of National Liquidity Aggregates, ratio to GDP United Kingdom
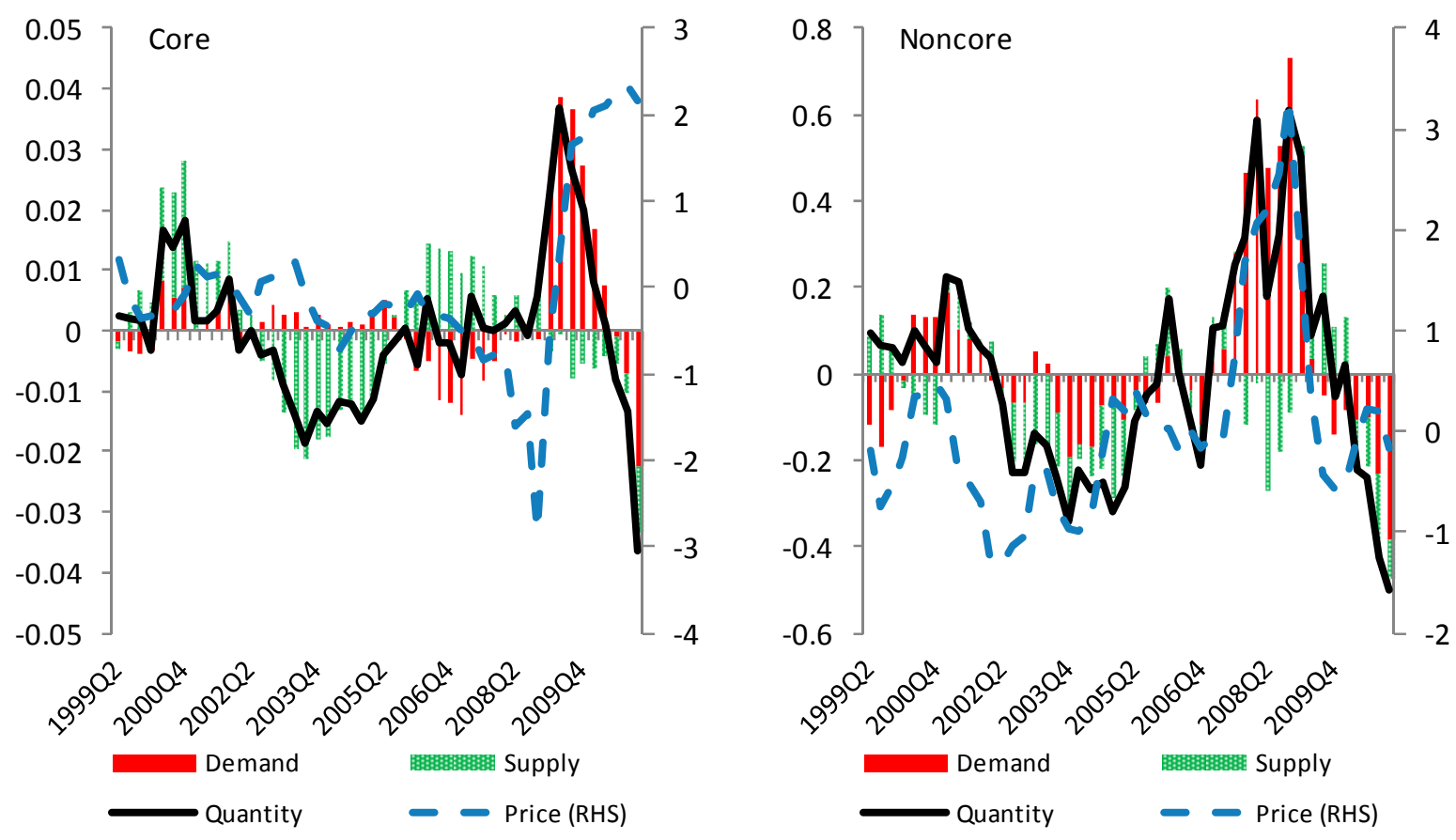

Japan

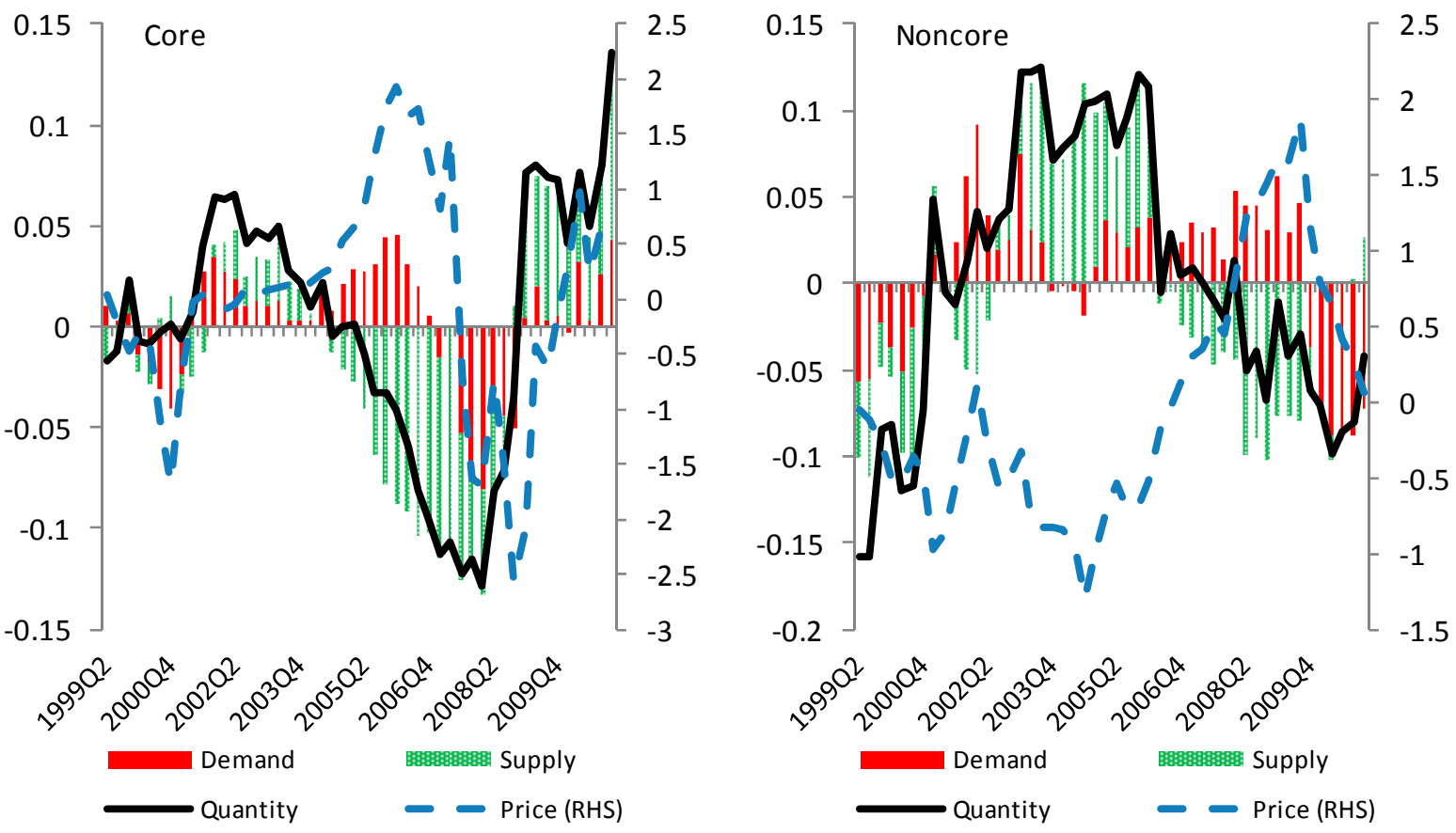


Figure 10. Supply and Demand Shocks, External Liabilities of G4 countries to BIS Reporting Banks

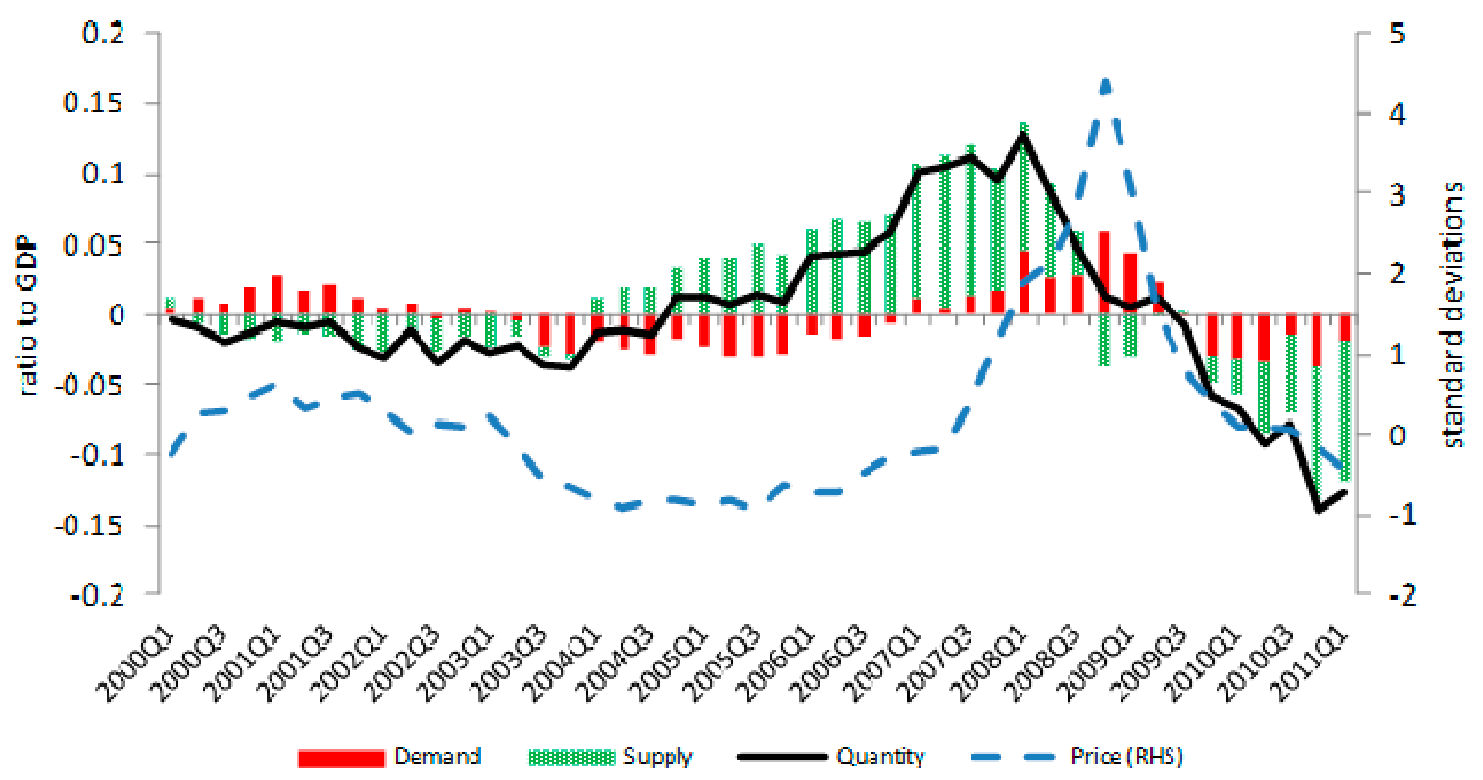

Figure 11. Supply and Demand Shocks, External Liabilities of other countries to BIS Reporting Banks 1/

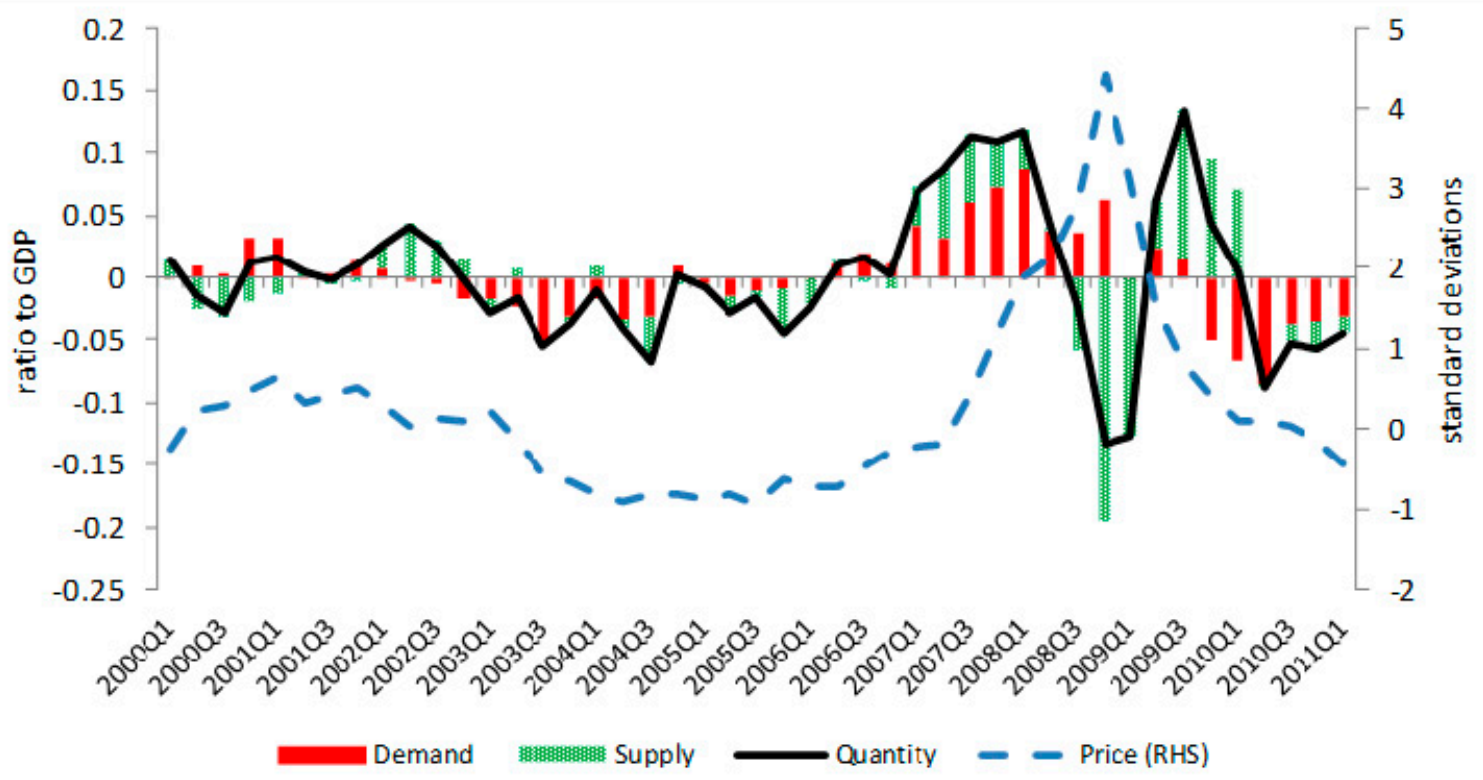

Sources: BIS, Bloomberg, Haver and Fund staff calculations.

$1 /$ Please refer to Section $V$ for a complete list of non-G4 countries in the sample. 
Figure 12. Impact of Core Demand Shock on Real GDP, ${ }^{1}$ Change in Level of Real GDP After 2 Quarters

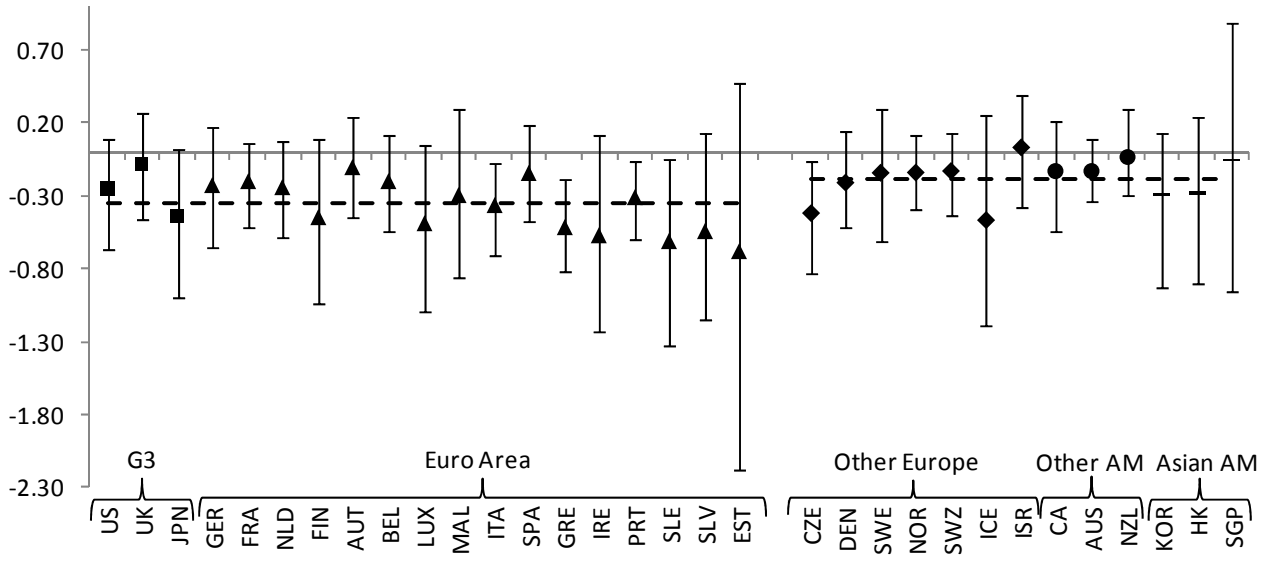

After 4 Quarters

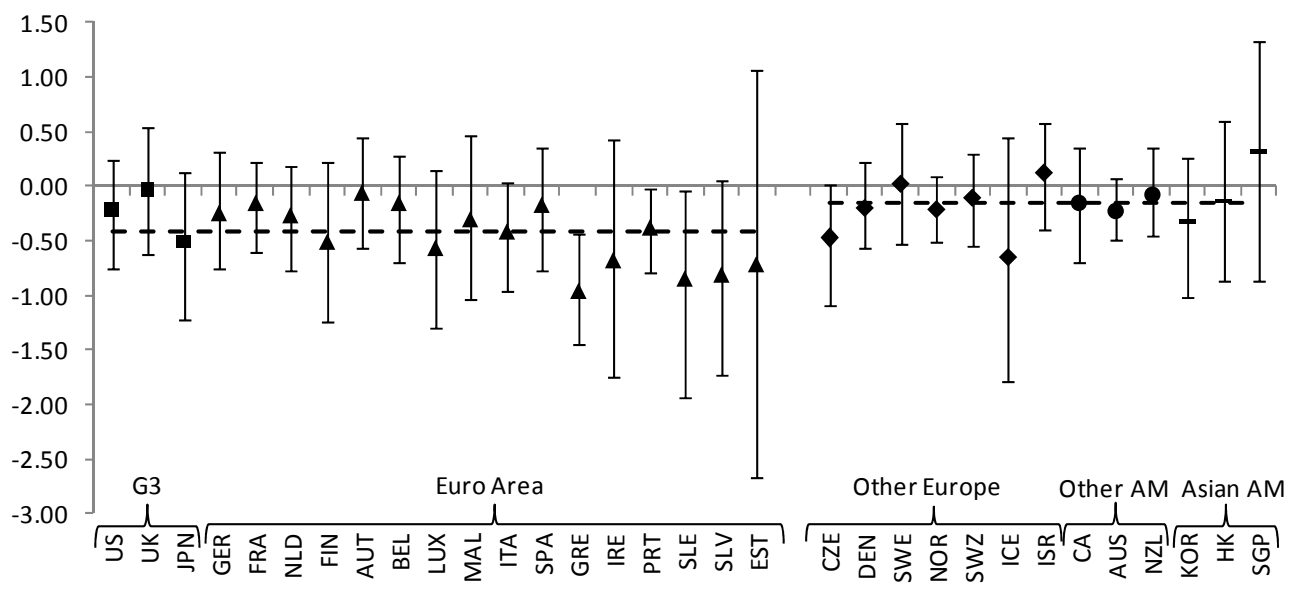

After 8 Quarters

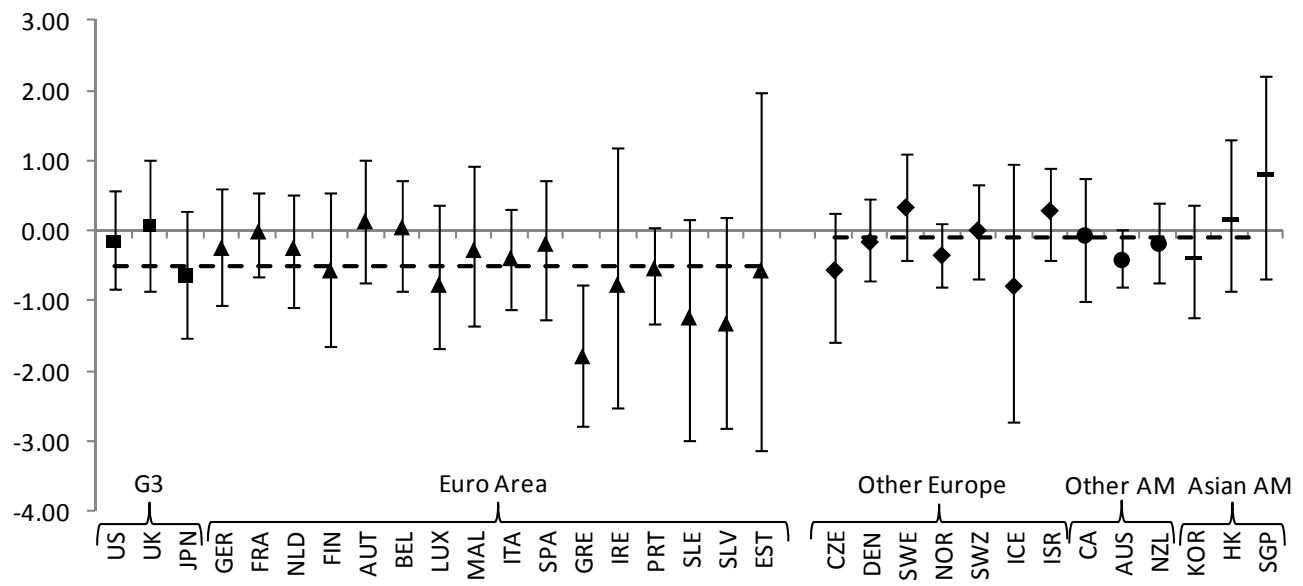

${ }^{1}$ Dashed line denotes the average among subgroups. $5^{\text {th }}$ and the $95^{\text {th }}$ percentile of the bootstrap distribution are plotted together with the median of the distribution. 
Figure 13. Impact of Core Supply Shock on Real GDP, ${ }^{1}$ Change in Level of Real GDP After 2 Quarters

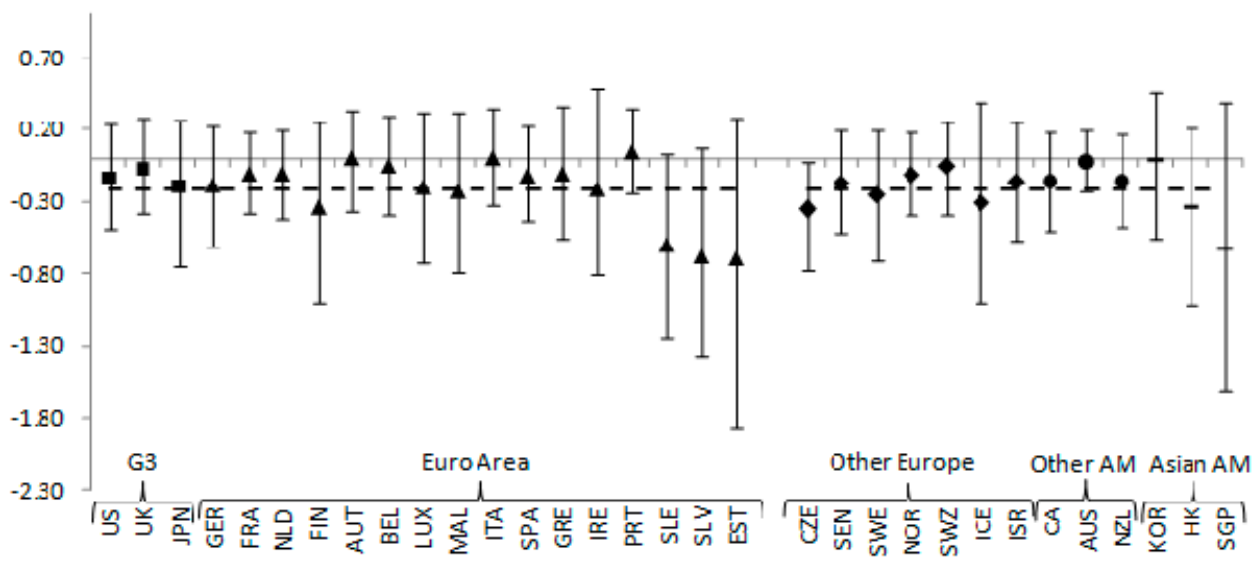

After 4 Quarters

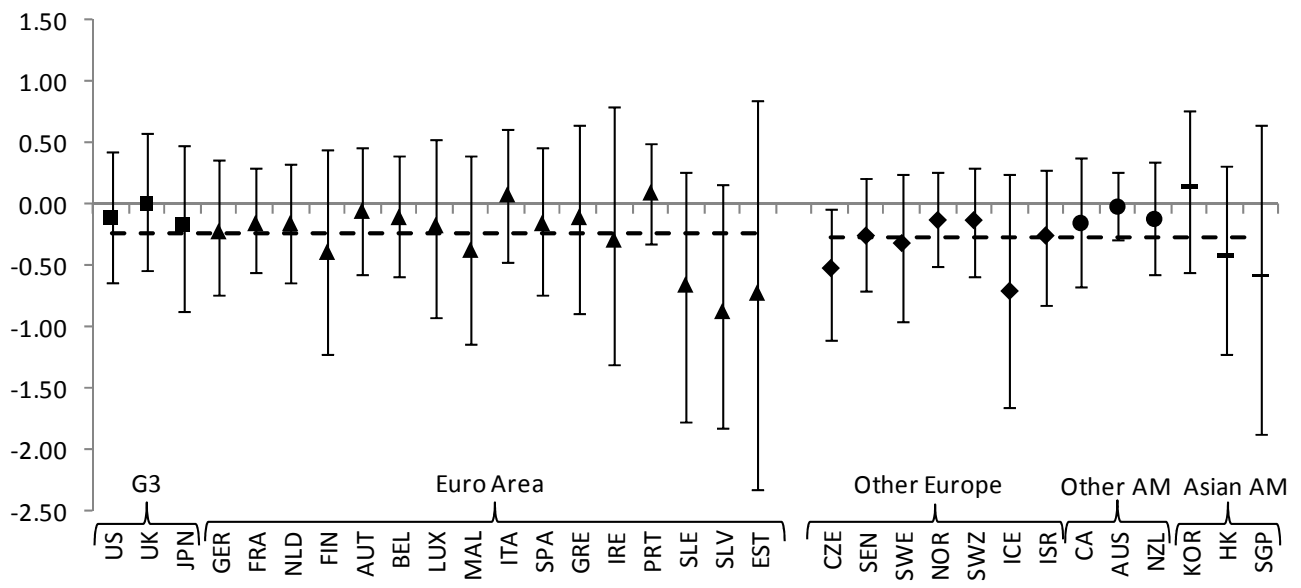

After 8 Quarters

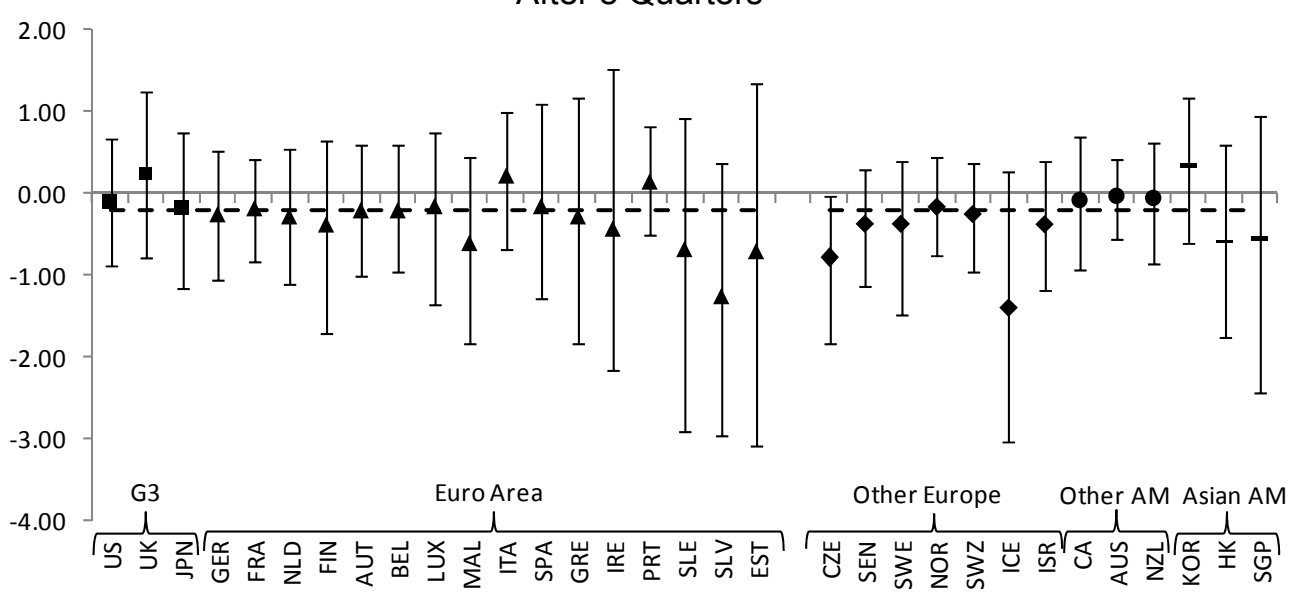

${ }^{1}$ Dashed line denotes the average among subgroups. $5^{\text {th }}$ and the $95^{\text {th }}$ percentile of the bootstrap distribution are plotted together with the median of the distribution. 
Figure 14. Impact of Noncore Demand Shock on Real GDP, ${ }^{1}$ Change in Level of Real GDP After 2 Quarters

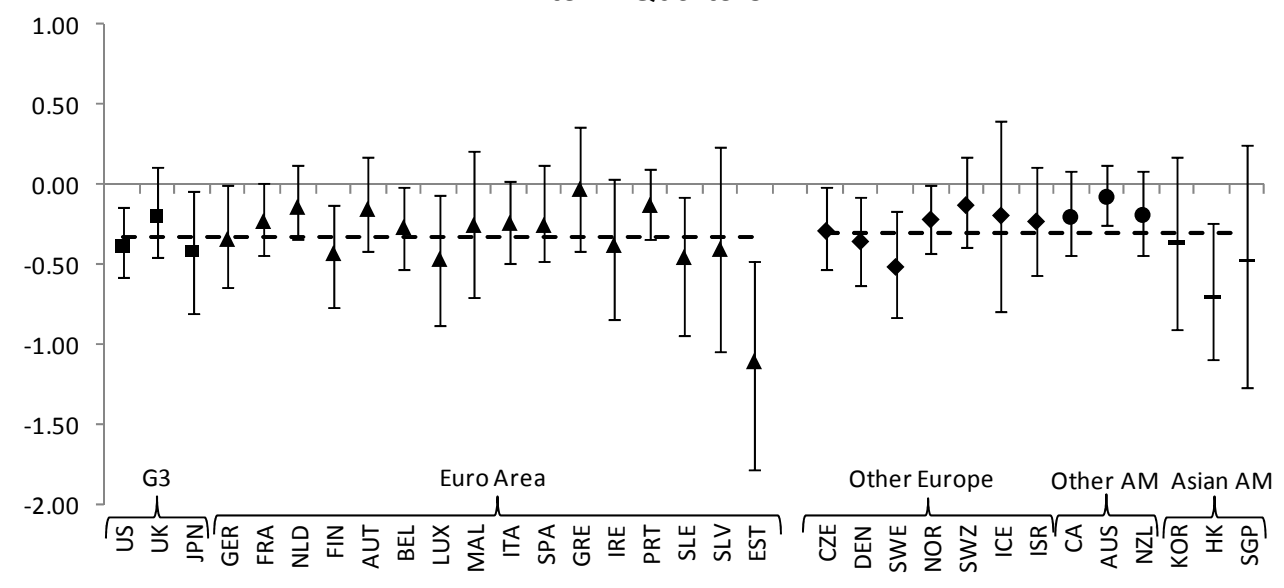

After 4 Quarters

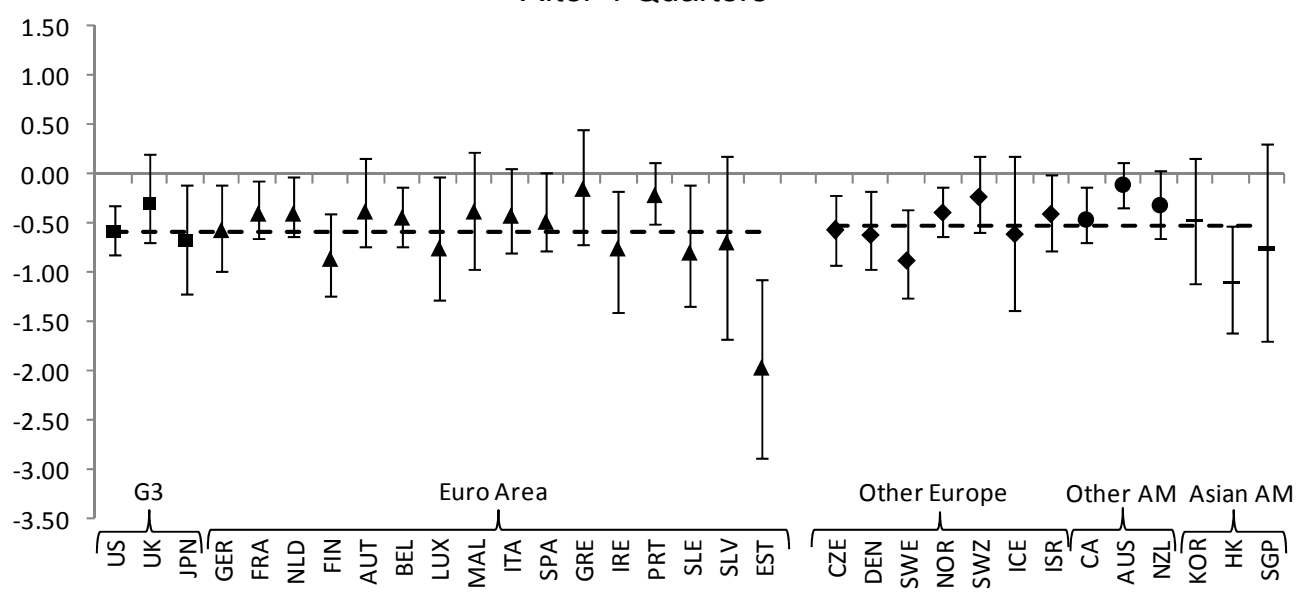

After 8 Quarters

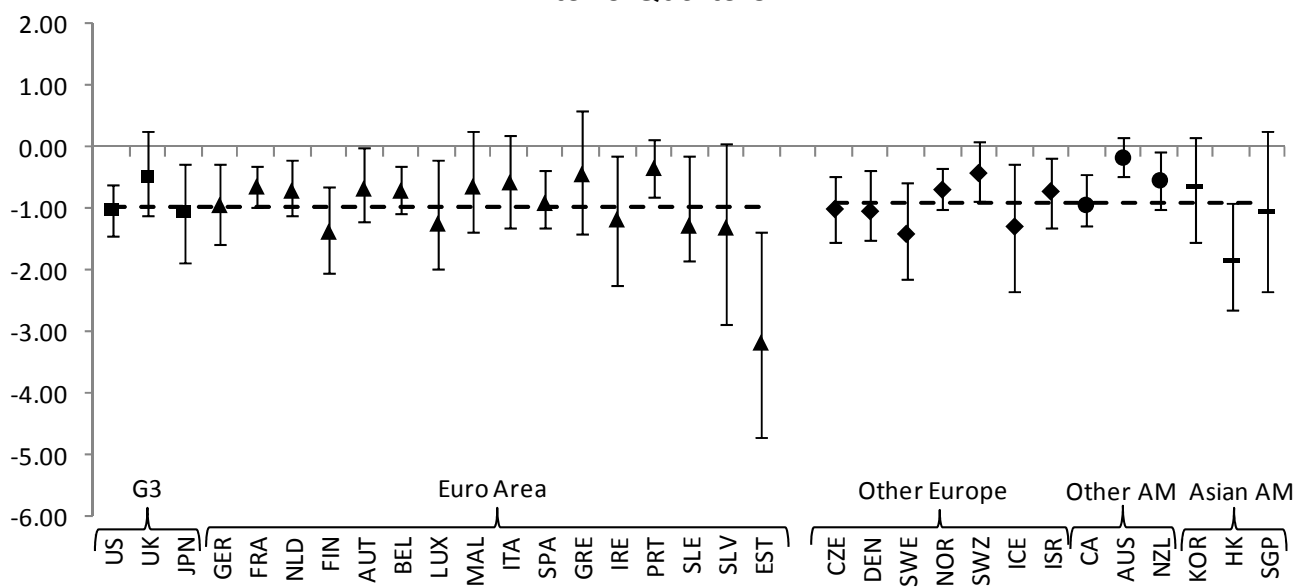

${ }^{1}$ Dashed line denotes the average among subgroups. $5^{\text {th }}$ and the $95^{\text {th }}$ percentile of the bootstrap distribution are plotted together with the median of the distribution. 
Figure 15. Impact of Noncore Supply Shock on Real GDP, ${ }^{1}$ Change in Level of Real GDP After 2 Quarters

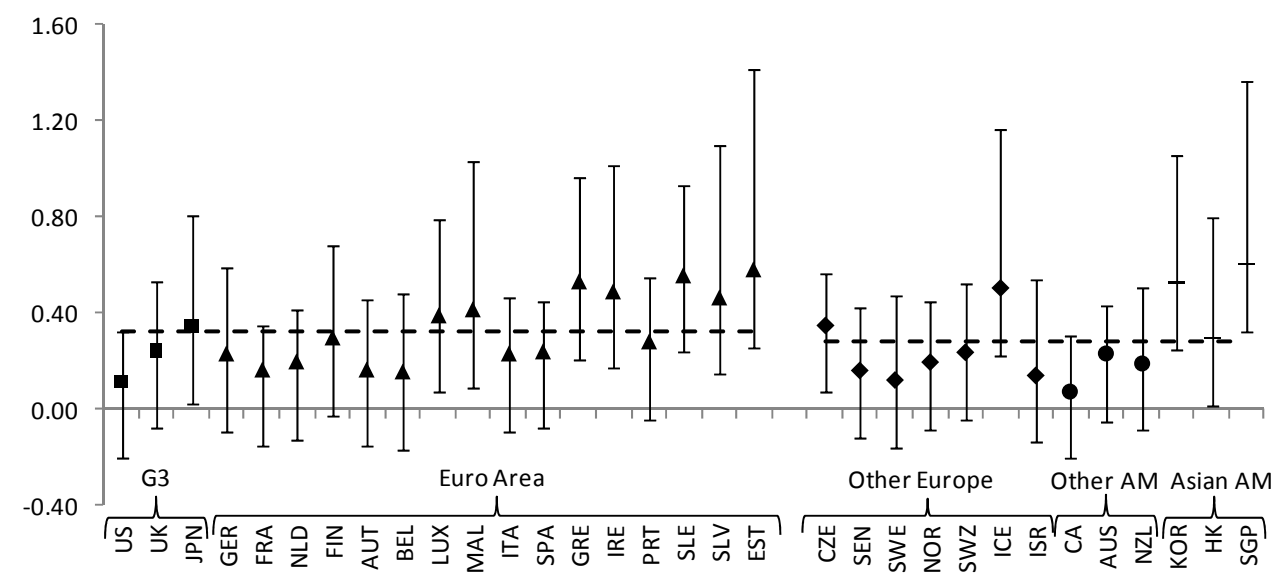

After 4 Quarters

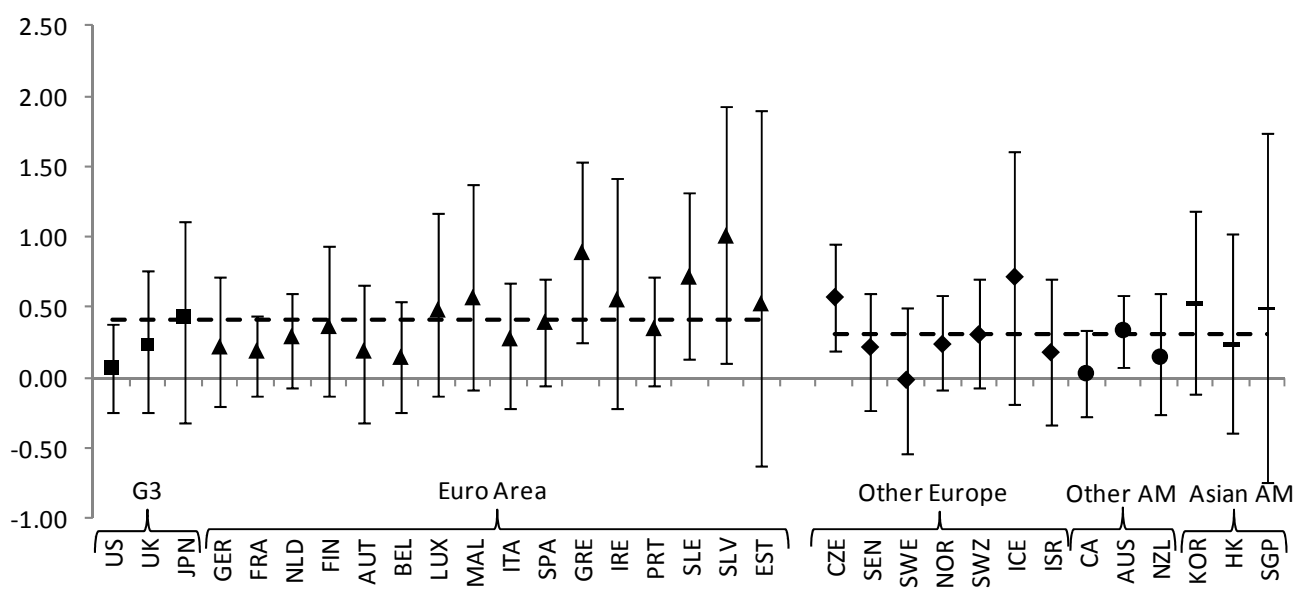

After 8 Quarters

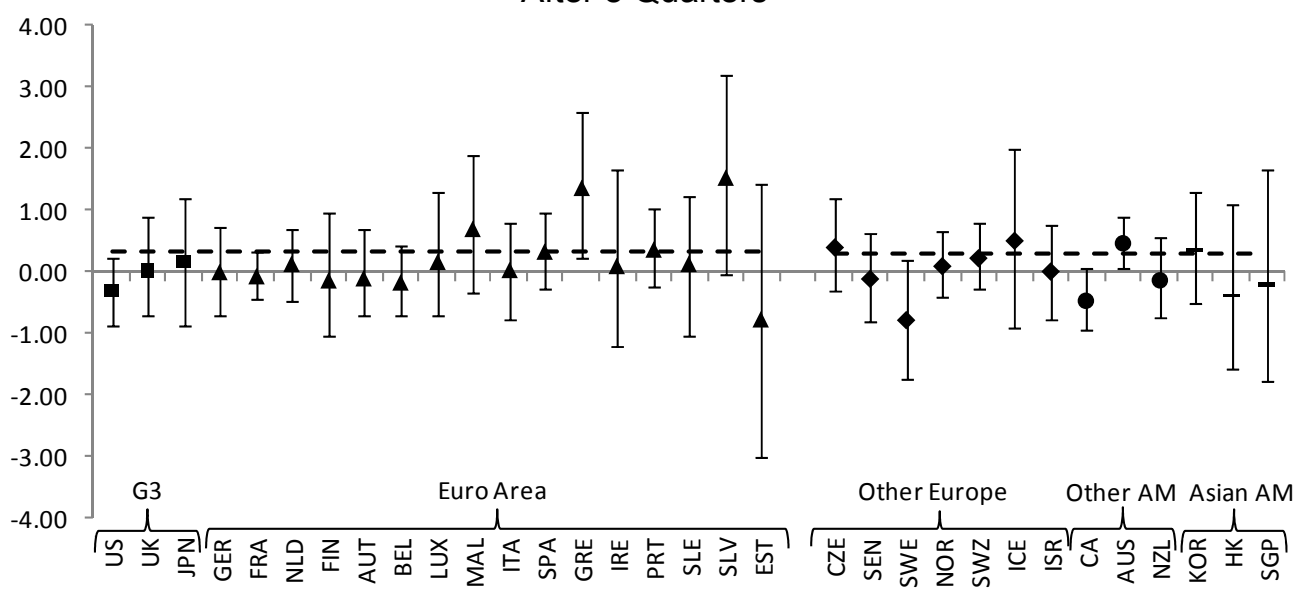

${ }^{1}$ Dashed line denotes the average among subgroups. $5^{\text {th }}$ and the $95^{\text {th }}$ percentile of the bootstrap distribution are plotted together with the median of the distribution. 
Table 1. Unit Root Tests of Liquidity Price and Quantity Indicators, p-values

\begin{tabular}{lcc}
\hline \multicolumn{1}{c}{ Variable } & ADF test & PP test \\
\hline Core liquidity price index & 0.1610 & 0.4556 \\
Noncore liquidity price index & 0.4546 & 0.6538 \\
G4 core liquidity, ratio to GDP & 0.9143 & 0.8834 \\
G4 noncore liquidity, ratio to GDP & 0.5461 & 0.9991 \\
G4 core liquidity, trillion dollars & 0.0465 & 0.4154 \\
G4 noncore liquidity, trillion dollars & 0.8765 & 0.9305 \\
\hline
\end{tabular}

Sources: Fund staff calculations.

Table 2. Estimation of Linear Trends

\begin{tabular}{lcc}
\hline \multicolumn{1}{c}{ Variable } & Core Liquidity, Ratio to GDP & $\begin{array}{c}\text { Noncore Liquidity, Ratio to } \\
\text { GDP }\end{array}$ \\
\hline Constant & $0.8379^{* * *}$ & $1.0516^{* * *}$ \\
Time & $0.0054^{* * *}$ & $0.0103^{* * *}$ \\
\hline Adjusted R-squared & 0.8201 & 0.8175 \\
Durbin Watson statistic & 0.1256 & 0.1210 \\
\hline
\end{tabular}

Sources: Fund staff calculations.

Notes: ${ }^{* * *}$ denotes significance at 1 percent. 
Table 3. Impact of Funding Shocks on Growth: Benchmark Model, Q1 1999-Q1 2011

\begin{tabular}{|c|c|c|c|c|c|c|c|c|c|}
\hline & (1) & (2) & (3) & (4) & (5) & (6) & (7) & (8) & (9) \\
\hline \multirow[t]{2}{*}{$\overline{\text { Real GDP growth rate }} \mathrm{t}_{\mathrm{t}-1}$} & $0.318^{\star \star \star}$ & $0.304^{* \star \star}$ & $0.267^{\star \star \star}$ & $0.413^{\star \star \star}$ & $0.450^{\star \star \star}$ & $0.437^{\star \star \star}$ & $0.347^{\star \star \star *}$ & $0.392^{\star \star *}$ & $0.364^{* \star \star}$ \\
\hline & $(3.803)$ & $(3.590)$ & $(2.793)$ & $(4.896)$ & $(4.992)$ & $(4.753)$ & $(2.851)$ & $(3.839)$ & $(3.037)$ \\
\hline \multirow[t]{2}{*}{ Policy rate ${ }_{t-1}$} & $-0.212^{*}$ & -0.134 & -0.158 & -0.177 & -0.118 & -0.114 & $-0.241^{* *}$ & -0.040 & $-0.197^{\star *}$ \\
\hline & $(-1.802)$ & $(-1.277)$ & $(-1.459)$ & $(-1.534)$ & $(-1.096)$ & $(-1.156)$ & $(-2.289)$ & $(-1.213)$ & $(-2.017)$ \\
\hline \multirow[t]{2}{*}{ Headline inflation $_{\mathrm{t}}$} & $-0.175^{\star \star \star}$ & -0.112 & -0.117 & $-0.158^{*}$ & $-0.136^{*}$ & $-0.131^{*}$ & -0.069 & $-0.158^{* \star *}$ & -0.059 \\
\hline & $(-2.708)$ & $(-1.435)$ & $(-1.536)$ & $(-1.767)$ & $(-1.942)$ & $(-1.711)$ & $(-0.907)$ & $(-3.441)$ & $(-1.017)$ \\
\hline \multirow[t]{2}{*}{ Core liquidity supply shock $t_{t-1}$} & 0.043 & & 0.165 & & & & 0.167 & & 0.162 \\
\hline & $(0.356)$ & & $(0.898)$ & & & & $(0.471)$ & & $(0.295)$ \\
\hline \multirow{2}{*}{ Core liquidity supply shock during crisis ${ }_{t-1}$} & $-1.094^{* \star *}$ & & $-0.697^{\star *}$ & & & & $-0.941^{*}$ & & -0.476 \\
\hline & $(-2.907)$ & & $(-2.541)$ & & & & $(-1.946)$ & & $(-0.792)$ \\
\hline \multirow[t]{2}{*}{ Core liquidity supply shock post crisis ${ }_{t-1}$} & $-0.836^{* * *}$ & & -0.226 & & & & 0.437 & & -0.069 \\
\hline & $(-3.610)$ & & $(-0.853)$ & & & & $(0.438)$ & & $(-0.075)$ \\
\hline \multirow[t]{2}{*}{ Core liquidity supply shock in $\mathrm{G} 4 \mathrm{t}-1$} & 0.067 & & -0.418 & & & & 0.188 & & -0.615 \\
\hline & $(0.386)$ & & $(-0.733)$ & & & & $(0.096)$ & & $(-0.337)$ \\
\hline \multirow[t]{2}{*}{ Core liquidity demand shock $\mathrm{t}_{\mathrm{t}-1}$} & & -0.082 & -0.160 & & & & -0.167 & & -0.028 \\
\hline & & $(-0.461)$ & $(-0.769)$ & & & & $(-0.641)$ & & $(-0.117)$ \\
\hline \multirow[t]{2}{*}{ Core liquidity demand shock during crisis $t-1$} & & $-1.644^{\star * *}$ & $-1.525^{\star \star *}$ & & & & $-1.314^{\star \star *}$ & & $-1.394^{\star * *}$ \\
\hline & & $(-4.494)$ & $(-4.725)$ & & & & $(-3.681)$ & & $(-2.695)$ \\
\hline \multirow[t]{2}{*}{ Core liquidity demand shock post crisis $t_{t-1}$} & & $1.024^{* *}$ & $1.194^{* \star *}$ & & & & 1.872 & & 1.027 \\
\hline & & $(2.542)$ & $(3.000)$ & & & & $(0.972)$ & & $(0.664)$ \\
\hline \multirow[t]{2}{*}{ Core liquidity demand shock in $\mathrm{G} 4 \mathrm{t}-1$} & & $0.244^{\star *}$ & $0.276^{*}$ & & & & 1.062 & & 0.106 \\
\hline & & $(2.157)$ & $(1.670)$ & & & & $(1.091)$ & & $(0.185)$ \\
\hline \multirow[t]{2}{*}{ Noncore liquidity supply shock ${ }_{t-1}$} & & & & $0.205^{* * *}$ & & 0.198 & -0.024 & & 0.214 \\
\hline & & & & $(2.600)$ & & $(0.862)$ & $(-0.061)$ & & $(0.704)$ \\
\hline \multirow[t]{2}{*}{ Noncore liquidity supply shock during crisis $\mathrm{t}_{\mathrm{t}-1}$} & & & & 0.159 & & 0.011 & -0.480 & & -0.247 \\
\hline & & & & $(1.514)$ & & $(0.055)$ & $(-1.495)$ & & $(-0.831)$ \\
\hline \multirow[t]{2}{*}{ Noncore liquidity supply shock post crisis ${ }_{t-1}$} & & & & -0.326 & & $-0.747^{\star * *}$ & 0.774 & & 0.149 \\
\hline & & & & $(-1.606)$ & & $(-2.959)$ & $(0.388)$ & & $(0.079)$ \\
\hline \multirow[t]{2}{*}{ Noncore liquidity supply shock in $\mathrm{G} 4 \mathrm{t}-1$} & & & & $-0.180^{*}$ & & 0.020 & 2.377 & & -0.438 \\
\hline & & & & $(-1.646)$ & & $(0.046)$ & $(0.876)$ & & $(-0.300)$ \\
\hline \multirow[t]{2}{*}{ Noncore liquidity demand shock $t_{t-1}$} & & & & & 0.064 & -0.101 & 0.047 & & -0.104 \\
\hline & & & & & $(0.524)$ & $(-0.317)$ & $(0.222)$ & & $(-0.359)$ \\
\hline \multirow[t]{2}{*}{ Noncore liquidity demand shock during crisis $\mathrm{t}_{\mathrm{t}-1}$} & & & & & $-0.836^{\star * *}$ & $-0.594^{*}$ & -0.110 & & -0.024 \\
\hline & & & & & $(-3.649)$ & $(-1.671)$ & $(-0.437)$ & & $(-0.063)$ \\
\hline \multirow[t]{2}{*}{ Noncore liquidity demand shock post crisis $t-1$} & & & & & $-1.061^{*}$ & $-0.847^{*}$ & 0.939 & & 0.729 \\
\hline & & & & & $(-1.944)$ & $(-1.686)$ & (1.098) & & $(0.772)$ \\
\hline \multirow[t]{2}{*}{ Noncore liquidity demand shock in $\mathrm{G} 4 \mathrm{t}-1$} & & & & & 0.224 & 0.090 & -0.811 & & 0.206 \\
\hline & & & & & (1.007) & $(0.260)$ & $(-0.773)$ & & $(0.311)$ \\
\hline \multirow[t]{2}{*}{ External claims ${ }_{t-1}$} & & & & & & & & -0.011 & -0.009 \\
\hline & & & & & & & & $(-1.075)$ & $(-0.708)$ \\
\hline \multirow[t]{2}{*}{ Constant } & $5.041^{\star \star *}$ & $4.054^{\star \star \star}$ & $4.661^{\star \star *}$ & $4.061^{\star \star \star}$ & $3.352^{\star \star *}$ & $3.374^{\star \star \star}$ & $4.828^{\star \star \star}$ & $3.517^{\star \star \star}$ & $4.468^{\star \star \star}$ \\
\hline & $(5.934)$ & $(5.264)$ & $(5.381)$ & $(4.610)$ & $(4.668)$ & $(4.265)$ & $(5.315)$ & $(6.048)$ & (4.165) \\
\hline Number of groups & 33 & 33 & 33 & 33 & 33 & 33 & 33 & 34 & 33 \\
\hline Number of observations & 1,192 & 1,192 & 1,192 & 1,192 & 1,192 & 1,192 & 1,192 & 1,331 & 1,192 \\
\hline
\end{tabular}

Source: IMF World Economic Outlook, Bloomberg, BIS, Staff calculations

Note: $z$-statistics in parentithesis. ${ }^{* * *},{ }^{* *},{ }^{*}$ denote significance at $1 \% .5 \%$ and $10 \%$, respectively. Two-step using Windmeijer standard errors. 
Table 4. Impact of Funding Shocks on Growth: Separate Time Periods, Q1 1999-Q1 2011

\begin{tabular}{|c|c|c|c|c|c|c|c|c|c|}
\hline & (1) & (2) & (3) & (4) & (5) & (6) & (7) & (8) & (9) \\
\hline \multirow[t]{2}{*}{ Real GDP growth rate $\mathrm{t}_{\mathrm{t}-1}$} & $0.305^{\star * *}$ & $0.302^{* \star *}$ & $0.296^{* \star *}$ & $0.420^{\star \star *}$ & $0.452^{* * *}$ & $0.435^{\star * *}$ & $0.341^{* * *}$ & $0.392^{* * *}$ & $0.328^{* * *}$ \\
\hline & (3.632) & (3.786) & (3.379) & $(4.918)$ & $(4.976)$ & $(4.674)$ & $(2.717)$ & $(3.839)$ & $(2.975)$ \\
\hline \multirow[t]{2}{*}{ Policy rate $t_{t-1}$} & $-0.224^{*}$ & -0.138 & -0.153 & -0.182 & -0.129 & -0.121 & -0.182 & -0.040 & $-0.216^{*}$ \\
\hline & $(-1.894)$ & $(-1.368)$ & $(-1.404)$ & $(-1.604)$ & $(-1.250)$ & $(-1.185)$ & $(-1.564)$ & $(-1.213)$ & $(-1.750)$ \\
\hline \multirow[t]{2}{*}{ Headline inflation $_{\mathrm{t}}$} & $-0.169^{* *}$ & $-0.133^{*}$ & -0.122 & $-0.153^{*}$ & $-0.144^{* *}$ & $-0.143^{* *}$ & -0.102 & $-0.158^{* * *}$ & -0.107 \\
\hline & $(-2.433)$ & $(-1.952)$ & $(-1.466)$ & $(-1.910)$ & $(-2.051)$ & $(-1.986)$ & $(-1.214)$ & $(-3.441)$ & $(-1.535)$ \\
\hline \multirow[t]{2}{*}{ Core liquidity supply shock pre-crisis $t-1$} & 0.049 & & 0.073 & & & & 0.074 & & 0.079 \\
\hline & $(0.510)$ & & $(0.619)$ & & & & $(0.572)$ & & $(0.548)$ \\
\hline \multirow[t]{2}{*}{ Core liquidity supply shock during crisis $t-1$} & $-1.022^{* * *}$ & & $-0.545^{\star *}$ & & & & $-0.587^{* * *}$ & & $-0.677^{*}$ \\
\hline & $(-3.018)$ & & $(-2.193)$ & & & & $(-3.026)$ & & $(-1.955)$ \\
\hline \multirow[t]{2}{*}{ Core liquidity supply shock post crisis $\mathrm{t}-1$} & $-0.788^{* * *}$ & & -0.085 & & & & -0.000 & & 0.105 \\
\hline & $(-4.493)$ & & $(-0.553)$ & & & & $(-0.000)$ & & $(0.142)$ \\
\hline \multirow[t]{2}{*}{ Core liquidity demand shock pre-crisis $t-1$} & & -0.124 & -0.076 & & & & 0.026 & & -0.078 \\
\hline & & $(-1.010)$ & $(-0.583)$ & & & & $(0.132)$ & & $(-0.336)$ \\
\hline \multirow[t]{2}{*}{ Core liquidity demand shock during crisis $\mathrm{t}-1$} & & $-1.785^{\star \star *}$ & $-1.604^{* * *}$ & & & & $-1.470^{\star * *}$ & & $-1.559^{* * *}$ \\
\hline & & $(-5.625)$ & $(-5.257)$ & & & & $(-4.696)$ & & $(-5.416)$ \\
\hline \multirow[t]{2}{*}{ Core liquidity demand shock post crisis ${ }_{t-1}$} & & $1.076^{* * *}$ & $1.095^{\star * *}$ & & & & 0.631 & & 0.943 \\
\hline & & $(4.248)$ & $(3.347)$ & & & & $(0.418)$ & & $(0.524)$ \\
\hline \multirow[t]{2}{*}{ Noncore liquidity supply shock pre-crisis $\mathrm{t}_{\mathrm{t}-1}$} & & & & $0.182^{\star \star *}$ & & 0.196 & $0.234^{* *}$ & & 0.161 \\
\hline & & & & $(3.787)$ & & $(1.535)$ & $(2.444)$ & & $(0.999)$ \\
\hline \multirow[t]{2}{*}{ Noncore liquidity supply shock during crisis ${ }_{t-1}$} & & & & $0.342^{* * *}$ & & $0.185^{* *}$ & -0.047 & & $-0.253^{*}$ \\
\hline & & & & $(2.632)$ & & $(2.287)$ & $(-0.481)$ & & $(-1.658)$ \\
\hline \multirow[t]{2}{*}{ Noncore liquidity supply shock post crisis ${ }_{t-1}$} & & & & -0.163 & & $-0.550^{* * *}$ & -0.394 & & -0.064 \\
\hline & & & & $(-0.828)$ & & $(-2.688)$ & $(-0.210)$ & & $(-0.030)$ \\
\hline \multirow[t]{2}{*}{ Noncore liquidity demand shock pre-crisis ${ }_{t-1}$} & & & & & 0.065 & -0.092 & -0.097 & & -0.069 \\
\hline & & & & & $(1.431)$ & $(-0.806)$ & $(-0.727)$ & & $(-0.485)$ \\
\hline \multirow[t]{2}{*}{ Noncore liquidity demand shock during crisis ${ }_{t-1}$} & & & & & $-0.786^{\star * *}$ & $-0.673^{* * *}$ & -0.138 & & -0.027 \\
\hline & & & & & $(-4.990)$ & $(-3.754)$ & $(-0.903)$ & & $(-0.202)$ \\
\hline \multirow[t]{2}{*}{ Noncore liquidity demand shock post crisis ${ }_{t-1}$} & & & & & $-0.961^{* * *}$ & $-0.926^{* *}$ & 0.482 & & 0.956 \\
\hline & & & & & $(-2.684)$ & $(-2.251)$ & $(0.611)$ & & $(0.961)$ \\
\hline \multirow[t]{2}{*}{ External claims $\mathrm{t}_{\mathrm{t}-1}$} & & & & & & & & -0.011 & -0.017 \\
\hline & & & & & & & & $(-1.075)$ & $(-1.268)$ \\
\hline \multirow[t]{2}{*}{ _cons } & $5.056^{* * *}$ & $4.377^{\star * *}$ & $4.406^{\star * *}$ & $4.075^{\star * *}$ & $3.471^{* * *}$ & $3.450^{* * *}$ & $4.528^{* * *}$ & $3.517^{\star \star *}$ & $5.109^{* * *}$ \\
\hline & $(6.152)$ & $(5.652)$ & $(4.918)$ & $(4.681)$ & $(5.197)$ & $(4.595)$ & $(4.644)$ & $(6.048)$ & $(5.012)$ \\
\hline Number of groups & 33 & 33 & 33 & 33 & 33 & 33 & 33 & 34 & 33 \\
\hline Number of observations & 1,192 & 1,192 & 1,192 & 1,192 & 1,192 & 1,192 & 1,192 & 1,331 & 1,192 \\
\hline
\end{tabular}

Source: IMF World Economic Outlook, Bloomberg, BIS, Staff calculations

Note: $z$-statistics in parentithesis. ${ }^{* * *},{ }^{* *},{ }^{*}$ denote significance at $1 \% .5 \%$ and $10 \%$, respectively. Two-step using Windmeijer standard errors. 
Table 5. Impact of Funding Shocks on Growth: G4-Specific Impacts, Q1 1999-Q1 2011

\begin{tabular}{|c|c|c|c|c|c|c|c|c|c|c|c|c|c|c|c|c|}
\hline & (1) & (2) & (3) & (4) & (5) & (6) & (7) & (8) & (9) & (10) & (11) & (12) & (13) & (14) & (15) & (16) \\
\hline \multirow[t]{2}{*}{ Real GDP growth rate $t_{t-1}$} & $0.361^{* \star *}$ & $0.358^{\star \star *}$ & $0.361^{\star \star *}$ & $0.368^{\star \star \star}$ & $0.420^{\star \star \star}$ & $0.408^{\star \star \star}$ & $0.413^{\star \star \star}$ & $0.419^{\star \star \star}$ & $0.425^{\star \star \star}$ & $0.419^{\star \star \star}$ & $0.427^{* \star *}$ & $0.423^{\star * *}$ & $0.450^{\star \star \star}$ & $0.448^{\star \star *}$ & $0.440^{* \star \star}$ & $0.442^{\star \star \star}$ \\
\hline & $(4.420)$ & $(4.353)$ & $(4.437)$ & $(4.506)$ & $(4.421)$ & $(4.419)$ & $(4.277)$ & $(4.320)$ & $(4.504)$ & $(4.833)$ & $(4.921)$ & $(4.778)$ & $(5.183)$ & $(4.613)$ & $(4.838)$ & $(5.010)$ \\
\hline \multirow[t]{2}{*}{ Policy rate $_{t-1}$} & -0.170 & -0.163 & -0.178 & -0.169 & $-0.190^{*}$ & $-0.190^{*}$ & -0.183 & $-0.190^{*}$ & -0.187 & -0.176 & $-0.194^{*}$ & -0.178 & $-0.169^{*}$ & -0.148 & -0.158 & -0.158 \\
\hline & $(-1.475)$ & $(-1.453)$ & $(-1.574)$ & $(-1.576)$ & $(-1.826)$ & $(-1.847)$ & $(-1.559)$ & $(-1.814)$ & $(-1.565)$ & $(-1.631)$ & $(-1.808)$ & $(-1.643)$ & $(-1.715)$ & $(-1.417)$ & $(-1.526)$ & $(-1.514)$ \\
\hline \multirow[t]{2}{*}{ Headline inflation $_{t}$} & $-0.170^{* *}$ & $-0.172^{* *}$ & $-0.176^{\star *}$ & $-0.176^{\star *}$ & $-0.172^{\star \star}$ & $-0.164^{\star \star}$ & $-0.182^{* *}$ & $-0.175^{* \star}$ & $-0.157^{\star *}$ & $-0.144^{*}$ & $-0.149^{\star}$ & $-0.146^{*}$ & $-0.131^{*}$ & $-0.135^{*}$ & $-0.136^{*}$ & $-0.154^{* *}$ \\
\hline & $(-2.310)$ & $(-2.321)$ & $(-2.400)$ & $(-2.412)$ & $(-2.085)$ & $(-2.035)$ & $(-2.152)$ & $(-2.107)$ & $(-2.294)$ & $(-1.738)$ & $(-1.737)$ & $(-1.857)$ & $(-1.834)$ & $(-1.778)$ & $(-1.750)$ & $(-1.962)$ \\
\hline \multirow[t]{2}{*}{ G4 core supply shock $t_{t-1}$} & $-0.449^{\star \star \star}$ & $-0.462^{\star \star *}$ & $-0.487^{\star \star \star}$ & $-0.466^{\star \star \star}$ & & & & & & & & & & & & \\
\hline & $(-2.636)$ & $(-2.691)$ & $(-2.793)$ & $(-2.607)$ & & & & & & & & & & & & \\
\hline \multirow[t]{2}{*}{ US core supply shock ${ }_{t-1}$} & 0.190 & & & & & & & & & & & & & & & \\
\hline & $(0.293)$ & & & & & & & & & & & & & & & \\
\hline \multirow[t]{2}{*}{ UK core supply shock $\mathrm{t}-1$} & & 0.541 & & & & & & & & & & & & & & \\
\hline & & $(0.724)$ & & & & & & & & & & & & & & \\
\hline \multirow[t]{2}{*}{ EA core supply shock $t_{t-1}$} & & & 0.577 & & & & & & & & & & & & & \\
\hline & & & $(1.234)$ & & & & & & & & & & & & & \\
\hline \multirow[t]{2}{*}{ JPN core supply shock $\mathrm{t}_{\mathrm{t}-1}$} & & & & 0.432 & & & & & & & & & & & & \\
\hline & & & & (0.913) & & & & & & & & & & & & \\
\hline \multirow[t]{2}{*}{ G4 core demand shock ${ }_{t-1}$} & & & & & $-0.303^{\star \star \star}$ & $-0.311^{\star \star \star}$ & $-0.293^{\star \star \star}$ & $-0.329^{\star \star *}$ & & & & & & & & \\
\hline & & & & & $(-4.265)$ & $(-4.163)$ & $(-3.927)$ & $(-4.689)$ & & & & & & & & \\
\hline \multirow[t]{2}{*}{ UK core demand shock ${ }_{t-1}$} & & & & & & 0.333 & & & & & & & & & & \\
\hline & & & & & & $(0.469)$ & & & & & & & & & & \\
\hline \multirow[t]{2}{*}{ EA core demand shock $t_{t-1}$} & & & & & & & 0.099 & & & & & & & & & \\
\hline & & & & & & & $(0.196)$ & & & & & & & & & \\
\hline \multirow[t]{2}{*}{ JPN core demand shock $\mathrm{t}_{\mathrm{t}-1}$} & & & & & & & & 0.679 & & & & & & & & \\
\hline & & & & & & & & $(0.626)$ & & & & & & & & \\
\hline \multirow[t]{2}{*}{ G4 noncore supply shock $\mathrm{t}_{\mathrm{t}-1}$} & & & & & & & & & $0.262^{* \star \star}$ & $0.250^{\star \star \star}$ & $0.203^{\star \star}$ & $0.217^{\star \star *}$ & & & & \\
\hline & & & & & & & & & (3.316) & $(3.177)$ & $(2.554)$ & $(2.804)$ & & & & \\
\hline \multirow[t]{2}{*}{ US noncore supply shock $t_{t-1}$} & & & & & & & & & $-0.608^{\star \star \star}$ & & & & & & & \\
\hline & & & & & & & & & $(-2.690)$ & & & & & & & \\
\hline UK noncore supply shock $\mathrm{t}_{\mathrm{t}-1}$ & & & & & & & & & & -1.717 & & & & & & \\
\hline & & & & & & & & & & $(-1.308)$ & & & & & & \\
\hline EA noncore supply shock $\mathrm{t}_{\mathrm{t}-1}$ & & & & & & & & & & & -0.019 & & & & & \\
\hline & & & & & & & & & & & $(-0.090)$ & & & & & \\
\hline JPN noncore supply shock $t_{t-1}$ & & & & & & & & & & & & -0.024 & & & & \\
\hline & & & & & & & & & & & & $(-0.048)$ & & & & \\
\hline G4 noncore demand shock ${ }_{t-1}$ & & & & & & & & & & & & & $-0.543^{\star \star \star}$ & $-0.546^{\star \star \star}$ & $-0.561^{1 \star \star}$ & $-0.566^{\star \star \star}$ \\
\hline & & & & & & & & & & & & & $(-4.291)$ & $(-3.888)$ & $(-4.070)$ & $(-4.505)$ \\
\hline UK noncore demand shock $\mathrm{t}_{\mathrm{t}-1}$ & & & & & & & & & & & & & & -0.562 & & \\
\hline & & & & & & & & & & & & & & $(-0.341)$ & & \\
\hline EA noncore demand shock ${ }_{t-1}$ & & & & & & & & & & & & & & & 0.239 & \\
\hline & & & & & & & & & & & & & & & $(0.333)$ & \\
\hline JPN noncore demand shock $t_{t-1}$ & & & & & & & & & & & & & & & & 0.087 \\
\hline & & & & & & & & & & & & & & & & $(0.190)$ \\
\hline _cons & 4. $361^{\star \star *}$ & $4.326^{\star \star *}$ & $4.508^{\star \star \star}$ & $4.460^{\star \star \star}$ & $4.337^{\star \star \star}$ & $4.401^{\star \star \star \star}$ & $4.240^{\star \star \star}$ & $4.408^{\star \star \star}$ & $4.417^{\star \star \star}$ & $4.030^{\star \star \star}$ & $4.105^{\star \star \star}$ & $4.069^{\star \star \star}$ & $3.762^{\star \star \star}$ & $3.717^{\star \star \star}$ & $3.943^{\star \star \star}$ & $3.972^{* * *}$ \\
\hline & $(5.121)$ & $(5.137)$ & $(5.479)$ & $(5.033)$ & $(4.967)$ & $(5.316)$ & $(4.490)$ & $(4.887)$ & $(4.923)$ & $(5.148)$ & $(5.206)$ & $(5.052)$ & $(5.037)$ & $(4.340)$ & $(5.019)$ & $(5.067)$ \\
\hline rho_ar & & & & & & & & & & & & & & & & \\
\hline Number of groups & 33.000 & 33.000 & 33.000 & 33.000 & 33.000 & 33.000 & 33.000 & 33.000 & 33.000 & 33.000 & 33.000 & 33.000 & 33.000 & 33.000 & 33.000 & 33.000 \\
\hline Number of observations & 1,192 & 1,192 & 1,192 & 1,192 & 1,192 & 1,192 & 1,192 & 1,192 & 1,192 & 1,192 & 1,192 & 1,192 & 1,192 & 1,192 & 1,192 & 1,192 \\
\hline
\end{tabular}




\section{Appendix: Composition of G4 Noncore Liabilities}

Figure 1. Structure of Noncore Liabilities: Japan and the United States

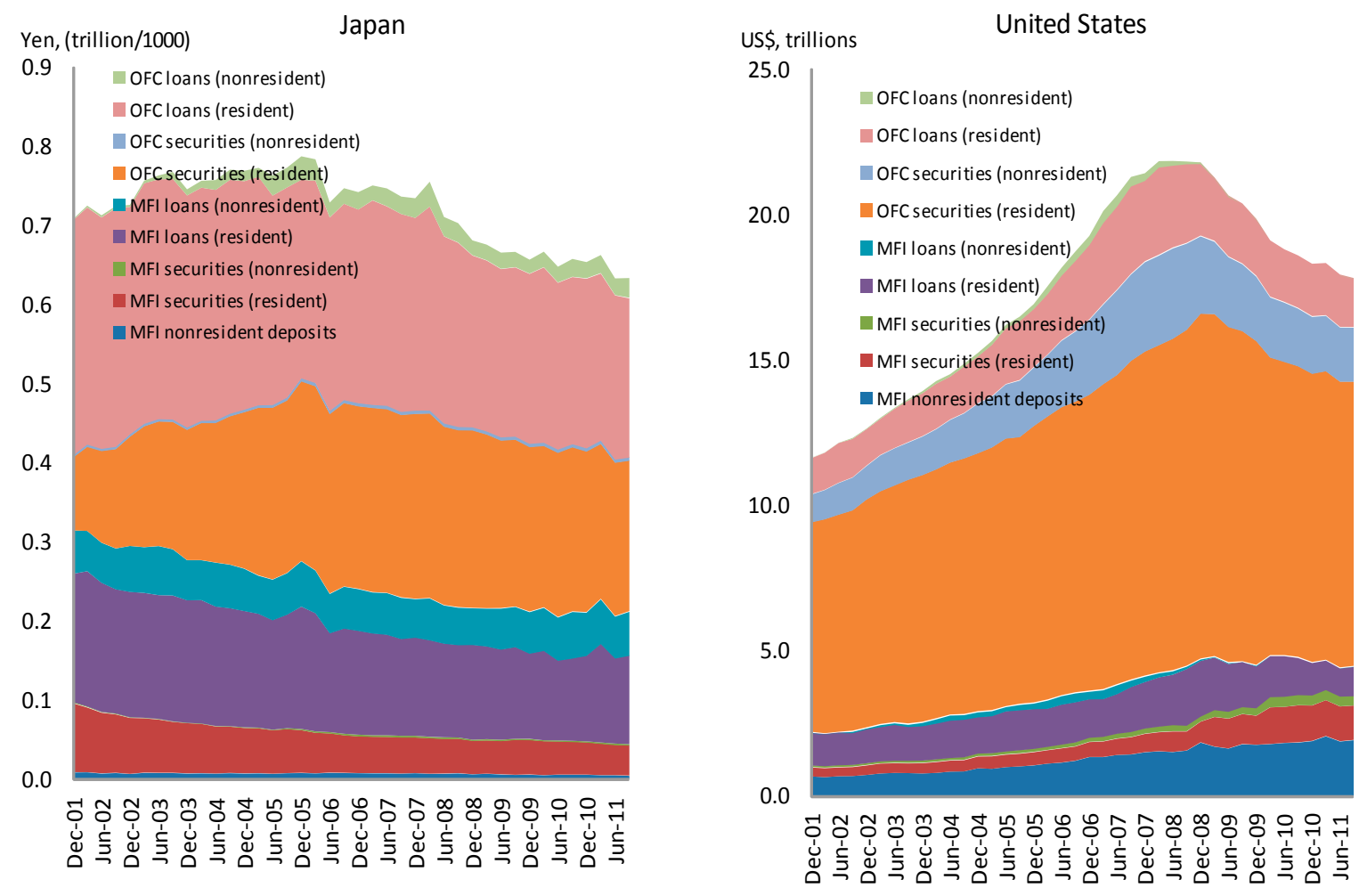

Source: IMF staff calculations.

Figure 2. Structure of Noncore Liabilities: Euro Area and the United Kingdom
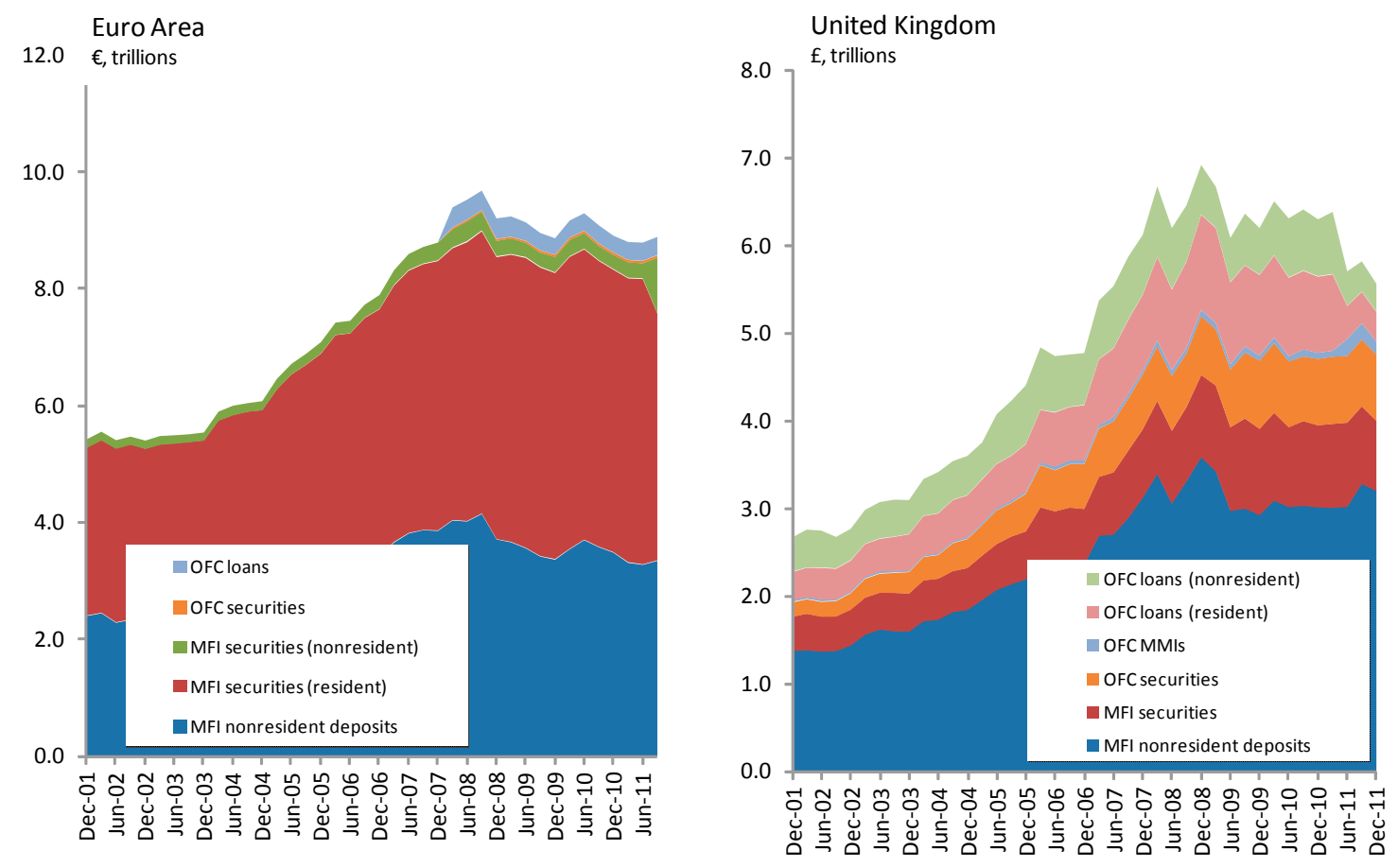

Source: IMF staff calculations. 
Figure 3. Behavior and Price of Global Liquidity

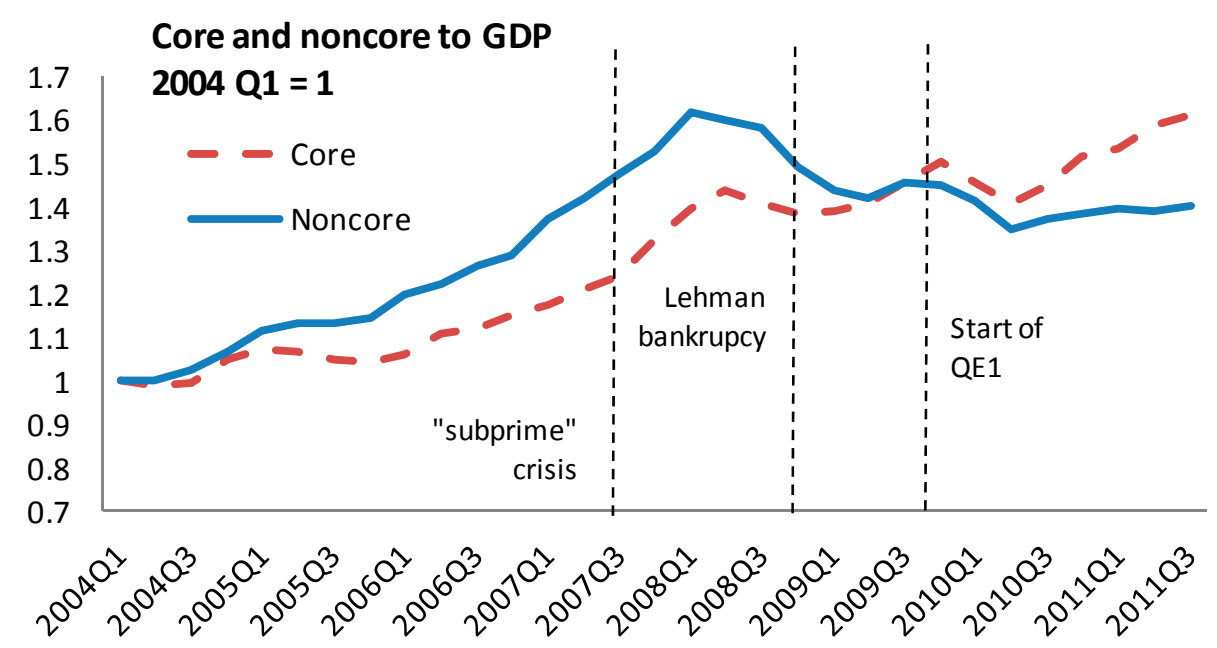

Ratio of Core to Noncore

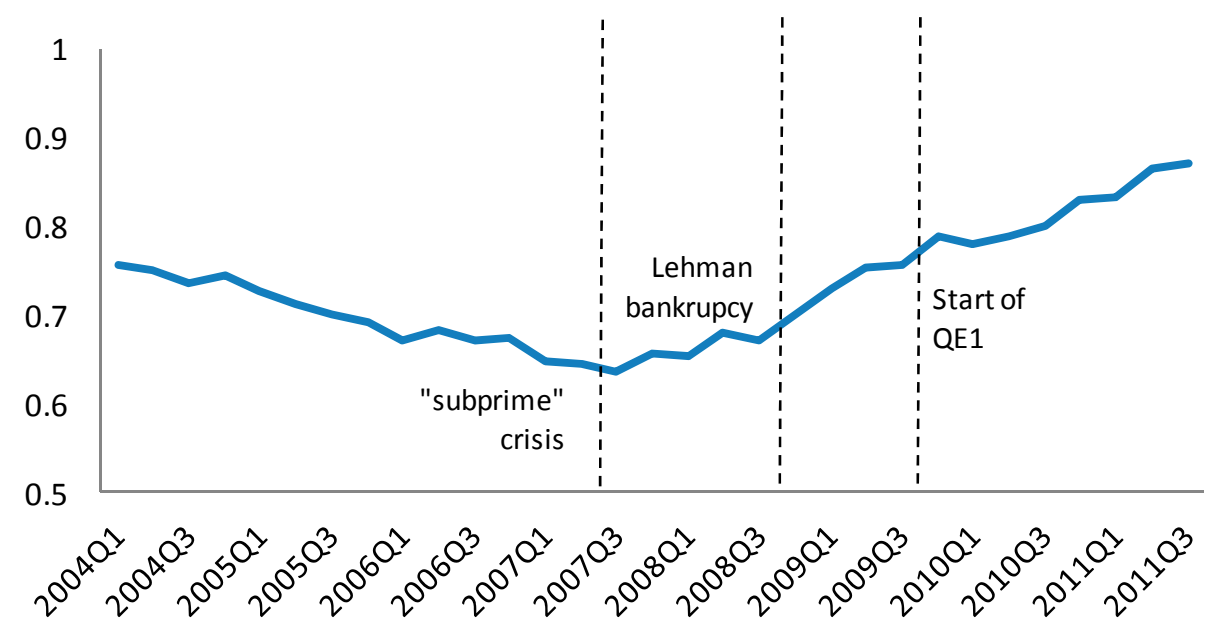

Noncore Liquidity Price Indicator

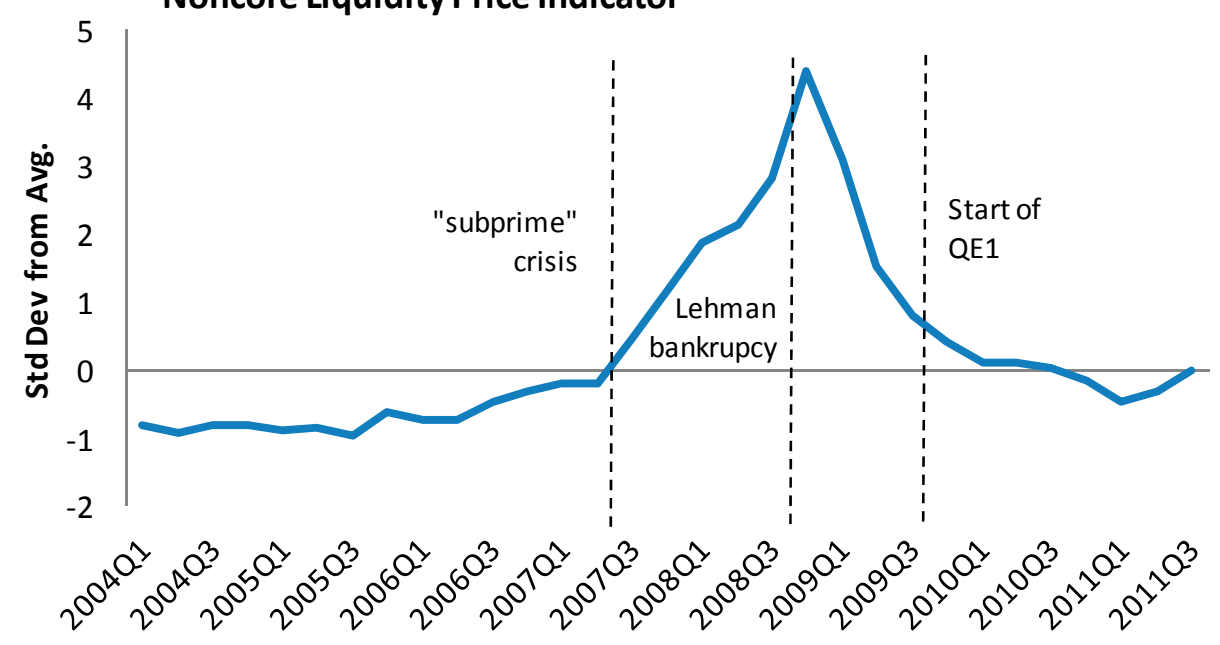

Source: Haver, Bloomberg, Staff Calculations 


\section{References}

Adrian, Tobias, and Hyun Song Shin, 2010, "Liquidity and Leverage," Journal of Financial Intermediation, Vol. 19, No. 3, pp. 418-37.

Alessi, L. and Detken, C., 2011, "Quasi Real Time Early Warning Indicators for Costly Asset Price Boom/Bust Cycles: A Role for Global Liquidity," European Journal of Political Economy, Vol 27 (3).

Bernanke, Ben, and Mark Gertler, 1989, “Agency Costs, Net Worth, and Business Fluctuations," The American Economic Review, Vol. 79, No. 1, pp. 14-31.

Bernanke, B, Gertler, M., and Gilchrist, S., "The Financial Accelerator In a Quantitative Business Cycle Framework," in Handbook of Macroeconomics, Chapter 21, pp. 1341-93, ed. by J. B. Taylor \& M. Woodford.

Borio, Claudio, R. McCauley, and P. McGuire, 2011, “Global Credit and Credit Booms,” BIS Quarterly Review, September.

Borio, Claudio, and P. Disyatat, 2011, “Global Imbalances and The Financial Crisis: Link or No Link?” BIS Working Paper No. 346, May.

Borio, Claudio, and Zhu, 2008, "Capital Regulation, Risk-Taking, and Monetary Policy: A Missing Link in the Transmission?” BIS Working Paper No. 268.

Bruno, Valentina, and Hyun Song Shin, 2011, "Capital Flows, Cross-Border Banking and Global Liquidity" (forthcoming).

Brunnermeier, M., 2009, "Financial Crises: Mechanisms, Prevention, and Management," in Macroeconomic Stability and Financial Regulation: Key Issues for the G20, ed. by M. Dewartripont, X. Freixas, and R. Portes.

Brunnermeier, M., and Yuliy Sannikov, 2011, “A Macroeconomic Model with a Financial Sector" (forthcoming).

Canova, F., and De Nicolo, G., 2002, "Monetary Disturbances Matter for Business Fluctuations in the G-7," Journal of Monetary Economics, Vol. 49, pp. 1131-59.

Committee of Global Financial Stability, 2011, “Global Liquidity-Concept, and Policy Implications," CGFS Paper 45 (Basel).

Darius, Reginald, and Sören Radde, 2010, “Can Global Liquidity Forecast Asset Prices?” IMF Working Paper 10/196 (Washington: International Monetary Fund). 
D’Agostino, A., and Surico, P., 2009, "Does Global Liquidity Help to Forecast U.S. Inflation?" Journal of Money, Credit, and Banking, Vol. 41, pp. 479-89.

Domanski, Dietrich, Ingo Fender, and Patrick McGuire, 2011, “Assessing Global Liquidity,” BIS Quarterly Review, (December).

De Nicolo, G., and Ivaschenko, I., 2009, "Global Liquidity, Risk Premiums and Growth Opportunities,” IMF Working Paper 09/52 (Washington: International Monetary Fund).

Eickmeier, S., and Ng, T., 2011, "How do Credit Supply Shocks Propagate Internationally? A GVAR Approach," CEPR Discussion Paper No. 8720, (December).

European Central Bank, 2011, "Global Liquidity: Measurement and Financial Stability Implications,” Financial Stability Review, Special Feature, (December).

European Central Bank, 2011, "Money and Credit as Early Warning Indicators of Asset Price Misalignments," Annual Report, Chapter 2, Box 2.

Fry, R., and Pagan, A., 2011, "Sign Restrictions in Structural Vector Autoregressions: A Critical Review," Journal of Economic Literature (forthcoming).

Gertler, M., and Kiyotaki, N., 2010, "Financial Intermediation and Credit Policy in Business Cycle Analysis," Handbook of Monetary Economics.

Giannone, D., Reichlin L., and Small, D., 2008, "Nowcasting: The Real-time Informational Content of Macroeconomic Data," Journal of Monetary Economics, Vol. 55(4), pp. 665-76.

Geanakoplos, J., 2010, “The Leverage Cycle,” Cowles Foundation Discussion Paper No. $1715 \mathrm{R}$.

Gerdesmeier, D., Reimers, H.-E. and Roffia, B., 2010, “Asset Price Misalignments and the Role of Money and Credit”, International Finance, Vol. 13, pp. 377-407.

Hahm, Joon-Ho, Shin, Hyun Song, and Shin, Kwanho, 2011, "Noncore Bank Liabilities and Financial Vulnerability," (forthcoming).

International Monetary Fund, 2011a, "How to Address the Systemic Part of Liquidity Risk," Global Financial Stability Report, Chapter 2 (April), World Economic and Financial Surveys (Washington).

, 2011b, "Global Liquidity Management—Possible Indicators to Monitor Global Liquidity,” Background Paper (SM/11/277) (Washington). 
,2011c, "The United States Spillover Report-2011 Article IV Consultation,"

IMF Country Report No. 11/203. Available via Internet:

http://www.imf.org/external/pubs/cat/longres.aspx?sk=25083.0

,2011d, "The United Kingdom Spillover Report-2011 Article IV Consultation,"

IMF Country Report No. 11/225. Available via Internet:

http://www.imf.org/external/pubs/cat/longres.aspx?sk=25114.0

,2011e, "How to Address the Systemic Part of Liquidity Risk, " Global Financial Stability Report, Chapter 2 (April), World Economic and Financial Surveys (Washington: International Monetary Fund).

,2011f, “Technical Note For G20 Sub-Working Group on Measuring Global Liquidity, " March, mimeo.

,2011g, "Analytics of Systemic Crises and the Role of Global Financial Safety Nets, " SM/11/107.

, 2011h, "Mapping Cross-Border Financial Linkages-A Supporting Case for Global Financial Safety Nets, ” SM/11/108.

,2011i, “Housing Finance and Financial Stability—Back to Basics?, ” Global Financial Stability Report, Chapter 3 (April), World Economic and Financial Surveys (Washington: International Monetary Fund).

,2011j, "Technical Note For G20 Sub-Working Group on Global Liquidity:

Progress Report on Assessing Global Liquidity, ” June, mimeo.

,2010a, “Global Liquidity Expansion: Effects on 'Receiving' Economies and Policy Response Options, ” in Global Financial Stability Report, Chapter 4 (April), World Economic and Financial Surveys (Washington: International Monetary Fund).

, 2010b, "Systemic Liquidity Risk: Improving the Resilience of Financial Institutions and Markets, ” in Global Financial Stability Report, Chapter 2 (October), World Economic and Financial Surveys (Washington: International Monetary Fund).

,2009, "Responding to the Financial Crisis and Measuring Systemic Risks, " in Global Financial Stability, Chapter 1 (April), World Economic and Financial Surveys (Washington: International Monetary Fund).

, 2009, "Lessons for Monetary Policy from Asset Price Fluctuations," in World Economic Outlook, Chapter 3 (October), World Economic and Financial Surveys (Washington: International Monetary Fund). 
, 2008, “Containing Systemic Risks and Restoring Financial Soundness, ” in Global Financial Stability, Chapter 3 (April), World Economic and Financial Surveys (Washington: International Monetary Fund).

, 2007, "What is Global Liquidity?" Box 1.3 in World Economic Outlook, Chapter 1 (October), World Economic and Financial Surveys (Washington: International Monetary Fund).

Jorda, Oscar, Schularick Moritz, Alan M. Taylor, 2011, "When Credit Bites Back: Leverage, Business Cycles, and Crises," Federal Reserve Bank of San Francisco, Working Paper Series, (November).

Kilian, Lutz, 1998, “Small-Sample Confidence for Impulse Response Functions," The Review of Economics and Statistics, Vol. 80 (2), pp. 218-30.

Kilian, L., 2009, "Not All Oil Price Shocks Are Alike: Disentangling Demand and Supply Shocks in the Crude Oil Market," American Economic Review, Vol. 99:3, pp. 1053-69.

Kim, Hyun Jeong, Shin, Hyun Song, and Yun, Jaeho, 2012, "Monetary Aggregates and the Central Bank's Financial Stability Mandata", forthcoming

Krishnamurthy, A., and Vissing-Jorgensen, A., 2007, “The Demand for Treasury Debt," NBER Working Paper No. 12881 (Cambridge, Massachusetts: National Bureau of Economic Research).

Kiyotaki, N., and Moore, J., 1997, “Credit Cycles," The Journal of Political Economy, Vol. 105, No. 2, pp. 211-48.

Matheson, T., 2011, "Financial Conditions Indexes for the United States and Euro Area," IMF Working Paper 11/93 (Washington: International Monetary Fund).

McGuire, and von Goetz, 2009, “The US dollar Shortage in Global Banking," BIS Quarterly Review, pp. 47-63 (March).

Peersman, G., 2005 "What Caused the Early Millennium Slowdown? Evidence based on Vector Autoregressions," Journal of Applied Econometrics, Vol. 20 (2), pp. 185-207.

Poszar, Zoltan, Tobias Adrian, Adam Ashcraft, and Hayley Boesky, 2010, "Shadow Banking," Federal Reserve Bank of New York, Staff Report No. 458 (July).

Poszar, Zoltan, 2011 "Institutional Cash Pools and the Triffin Dilemma of the U.S. Banking System”, IMF Working Paper 11/190 (Washington: International Monetary Fund). 
Psalida, L. Effie, Sun, Tao, 2011, “Does G4 Liquidity Spill Over?,” IMF Working Paper 11/237 (Washington: International Monetary Fund).

Rüffer, Rasmus, and Livio Stracca, 2006, "What is Global Excess Liquidity, and Does it Matter?” ECB Working Paper No. 696 (Frankfurt: European Central Bank).

Schwarz, Gideon, 1978, "Estimating the Dimension of a Model," The Annals of Statistics 6(2), pp. 461-64.

Shin, Hyun Song, and Kwanho Shin, 2011, "Pro-cyclicality and Monetary Aggregates," NBER Working Paper Series No. 16836, February (Cambridge, Massachusetts: National Bureau of Economic Research).

Singh, Manmohan, 2011, "Velocity of Pledged Collateral," IMF Working Paper 11/256 (Washington: International Monetary Fund).

Sousa, João, and Andrea Zaghini, 2004, "Monetary Policy Shocks in the Euro Area and Global Liquidity Spillovers,” Bank of Italy Economic Working Papers No. 629.

Thomas, Alun, Martin Mühleisen, and Malika Pant, 2010, "Peaks, Spikes and Barrels: Modeling Sharp Movements in Oil Prices,” IMF Working Paper 10/186 (Washington: International Monetary Fund).

Tirole, Jean, 2011, "Illiquidity and All its Friends," Journal of Economic Literature, Vol. 49, Number 2, pp. 287-325.

Uhlig, H., 2005, 'What are the Effects of Monetary Policy on Output? Results from an Agnostic Identification Procedure," Journal of Monetary Economics, Vol. 52, pp. 381-419. 